\title{
Gear transmission dynamics: Effects of index and run out errors
}

\author{
A. Fernández-del-Rincón, M. Iglesias, A. de-Juan, A. Diez-Ibarbia, P. García, F. Viadero \\ Department of Structural and Mechanical Engineering, University of Cantabria, Avda. de los Castros s/n, \\ 39005 Santander, Spain \\ \{alfonso.fernandez, miguel.iglesias, ana.dejuan, alberto.diez, pablo.garcia \\ fernando.viadero\}@unican.es
}

\begin{abstract}
This work describes a non-linear dynamic model for the study of the vibration signals generated by gear transmissions. The developed model considers both the parametric excitations due to the variable compliance of bearings and gears, can handle changes in the transmitted torque and allows the integration of the dynamic equations quickly and accurately. This model has been developed previously by the authors to assess the profile deviations on the dynamic behavior of gear transmissions and its influence on the transmitted torque. It also includes the presence of gear defects as cracks and pitting during the calculation of meshing forces. In this paper, the model has been enhanced in order to include two common defects such as index errors and run out or eccentricity errors. Index errors occur as a result of a non-uniform angular distribution of the tooth profiles along the pitch circle. Run out appears due to the displacement of the geometric center of the gear with respect to the center of rotation of the shaft on which it is mounted. Although both errors are caused by different reasons, sometimes they have been confused because of their similitudes. The procedure for including both kinds of errors in the model is described and simulations under several transmitted torques are presented. The results are assessed and compared focusing the attention on certain transmission parameters and magnitudes as transmission error, load forces in the tooth flanks and demodulation techniques on the resulting vibratory signals.
\end{abstract}

Keywords: Gear, Bearings, Gear vibrations, Run out, Index error

\section{Nomenclature}

$A_{n}$

C

$G M F$

$B P F$

$d o f$

$e_{i}$

$e_{P j 1,2}$

$\mathbf{f}_{\mathbf{b}}$

$\mathbf{f}_{\text {Ext }}$

$\mathbf{f}_{\mathbf{R}}$

K

$L$

$L O A$

$L S R$

LTE

M

$R$

$r_{1}, r_{2}$

$u_{T j}$

pitch error amplitude of harmonic $n$

damping matrix

Gear Mesh Frequency

Ball Pass Frequency

degree of freedom

eccentricity error

are the index errors of pinion and wheel

bearing forces

external forces

meshing forces

stiffness matrix

superscript related with the tooth left flanks

Line of Action

Load Sharing Ratio

Loaded Transmission Error

mass matrix

superscript related with the tooth right flanks

position vectors for gear center

elastic deflection obtained at contact point $j$ under the force vector $F$ 

Z Gear number of teeth
$\delta_{j} \quad$ geometrical separations between teeth profiles at potential contact $j$
$\theta_{1}, \theta_{2} \quad$ rotation angles of gears
$\theta_{e i} \quad$ angular position of gear geometric center with respect to the actual center line

\section{Introduction}

The need of more reliable and efficient gear transmissions, with an increment of transmitted torques and speeds, has motivated the interest of researchers in the development of analytical tools that can provide a deeper understanding of the dynamics involved in these kinds of systems. These analytical models are currently being used for the improvement of the dynamic behavior of transmissions, enabling for example the reduction of the magnitude of the transmitted loads, attenuating the acoustic noise and vibration, and simultaneously increasing the reliability of the whole transmission. Furthermore, these tools can also provide an excellent basis for the development and validation of strategies and troubleshooting techniques based on vibration analysis. Therefore, this kind of analytical model could also play an important role on the development of specific techniques for machinery condition monitoring in non-stationary conditions.

The operation of machinery in non-stationary conditions is mainly related to changes in speed and load. Whilst the speed variation can be approached by the use of order tracking techniques and synchronous average, load variations involve changes in the dynamic parameters of the system as stiffness and damping. Therefore, it would be very interesting the development of such theoretical models which have the ability to simulate the consequences of load changes on the resulting vibration and its interaction with the presence of defects. Furthermore, such kinds of models would provide the basis for a better understanding of the noise sources involved on gear transmissions.

Bearing this objective in mind, the authors have been working on the development of advanced tools for the simulation of gear dynamics under different kinds of defects. Meshing forces, which are probably the most critical aspect of a gear model, have been formulated by means of an advanced combination of numerical and analytical formulations [2]. Subsequently, the procedure used for the meshing forces calculation was adapted in order to consider different types of tooth defects as cracks and pitting [4] as well as profile deviations [5]. Although these models are mainly focused on simulating the main features of gears, bearings have been also modelled, as they constitute a crucial part of mechanical transmissions [1]. This aspect, which includes a variable compliance model for bearings, has been included in the model for the assessment of the vibrations of gear transmissions due to transmitted torque [3].

This work presents an enhanced model for simulating mechanical transmissions, which includes index and run out errors. Index errors, also known as pitch errors or tooth spacing errors, are one of the most common errors that can be found in actual gears. Ideal gears should present the same distance between teeth profiles along the pitch circle. However, mismatches on the relative position between the cutting or finishing tools and the workpiece and also distortions during heat treatments, result in tooth displacements with respect to its ideal position. As a consequence, not only noise and vibration levels are notably increased [6]-[7] but also important overloads can appear due to the different load sharing between teeth pairs [8]-[9]. This is caused by the delays or advances in 
the tooth contacts compared to the expected instant when no indexing errors are present. Gear run out is due to displacement of the gear geometric center with respect to the center of rotation of the shaft on which it is mounted. Despite the fact that run out has a different origin, this error could give a similar pattern of symptoms as indexing errors, and also results in an effective accumulated pitch variation, which may lead to confusion. That is due to manufacturing errors on the gear bore but it could also be derived from shaft or bearing housing manufacturing errors as well as wrong mounting.

In this work, both index and run out errors have been considered in the enhanced model which also takes into account the non-linearity and variable compliance inherent to gears and bearings. Due to the capabilities of the model, it is possible to consider these kinds of errors in an easy and simply way, enabling quasi-static and dynamic simulations. The model simulates the static and dynamic behavior of a sample transmission with and without errors working under several load conditions. Thus, several transmission features as Load Sharing Ratio (LSR), Loaded Transmission Error (LTE) and dynamic forces at bearing level are obtained for each error type and they are analyzed and compared with those obtained without defects.

\section{Dynamic model and error formulation}

The model presented in this work has enhanced previous features that allow index and run out errors to be studied. Reader should check previous works, such as [5], for a more detailed description of the model and its particular application to the study of tooth profile deviations. Nevertheless, a brief summary of the main capabilities of gears and bearings advanced formulations is detailed next.

In the case of gears, a hybrid formulation is used for the calculation of tooth contact forces which involve a double approach, numerical and analytical (see [2] for further information). This aspect allows simulating complex contact conditions as those which arise near resonance, when contacts in the tooth back could be take place. Moreover, it gives an accurate picture regarding the load distribution between the active teeth pairs considering at the same time the coupling deflections between them. The calculation procedure involves the determination of the minimum distances between teeth profiles when gear location is known under the assumption of gear rigid bodies. Then, overlaps between teeth profiles are obtained and forces determined using the non-linear hybrid procedure.

On the other hand, bearings behavior is included by means of a non-linear variable compliance model [1]. In this case, only Hertzian forces are considered, neglecting elastic deflections of bearing races. Following a similar approach as that used for gears, the first step for bearing forces calculation requires the calculation of the ball-outer and ball-inner profile overlapping to obtain the corresponding force. Then, all the forces obtained for each active contact are added in order to obtain the resulting force.

Both gear and bearing forces are implemented in ad-hoc functions which are used to build a dynamic model in Simulink environment. Particular attention is given to the development of accurate methodologies for modeling defects, both in gears and bearings, which at the same time do not require an intensive computational effort in order to enable dynamic simulations. 
In this work, a transmission was simulated using this enhanced model. Fig. 1 shows a description of the transmission model developed, including the designation for the degrees of freedom (dof) considered in simulations. Each gear was supported in two bearings by a flexible shaft and three dof per each element (gear or bearing) was considered (two orthogonal translations and one rotation). Subscripts $R$ and $b$ are used to design gears and bearing related dof, which are furthermore grouped in vectors $\boldsymbol{q}_{i b j}=\left\{x_{i b j}, y_{i b j}, \theta_{i b j}\right\}^{T}$ and $\boldsymbol{q}_{i R j}=\left\{x_{i R j}, y_{i R j}, \theta_{i R j}\right\}^{T}$. Where $x_{i R j}$ means the displacement along the $x$-axis of gear $j$ of shaft $i$. Moreover, and additional rotational inertia was considered at transmission output. External torque was applied on the output inertia while angular position of the input shaft was prescribed in simulations. This approach circumvents the difficulties associated with defining working conditions in these kinds of problems when friction or damping is considered in simulations. Then a dynamic model with 19 dof is developed leading to equation (1)

$$
\begin{aligned}
& \ddot{\mathbf{q}}=\mathbf{M}^{-1}\left(\mathbf{f}_{E x t}(t)-\mathbf{C} \dot{\mathbf{q}}-\mathbf{K q}-\mathbf{f}_{b}(\mathbf{q})-\mathbf{f}_{R}(\mathbf{q}, \dot{\mathbf{q}})\right) \\
& \mathbf{q}=\left\{\mathbf{q}_{1 b 1}, \mathbf{q}_{1 R 1}, \mathbf{q}_{1 b 2}, \mathbf{q}_{2 b 1}, \mathbf{q}_{2 R 1}, \mathbf{q}_{2 b 2}, \theta_{O u t}\right\}^{T}
\end{aligned}
$$

Where $\mathbf{M}, \mathbf{C}$ and $\mathbf{K}$ are constant coefficient matrices, while vectors $\mathbf{f}_{\mathbf{b}}, \mathbf{f}_{\mathbf{R}}$ and $\mathbf{f}_{\text {Ext }}$ stands for non-linear bearing, meshing and external forces. Gear related non-linearity is removed from equation (1) by a quasi-static calculation of gear meshing stiffness for several positions along a meshing cycle under a certain transmitted torque. Then the resulting stiffness for each contacting point is store and used subsequently in dynamic simulations. More details regarding the particular procedure used for this task can be found in references [2] and [5].

The approach followed in the formulation of the role played by pitch and run out errors is described next.

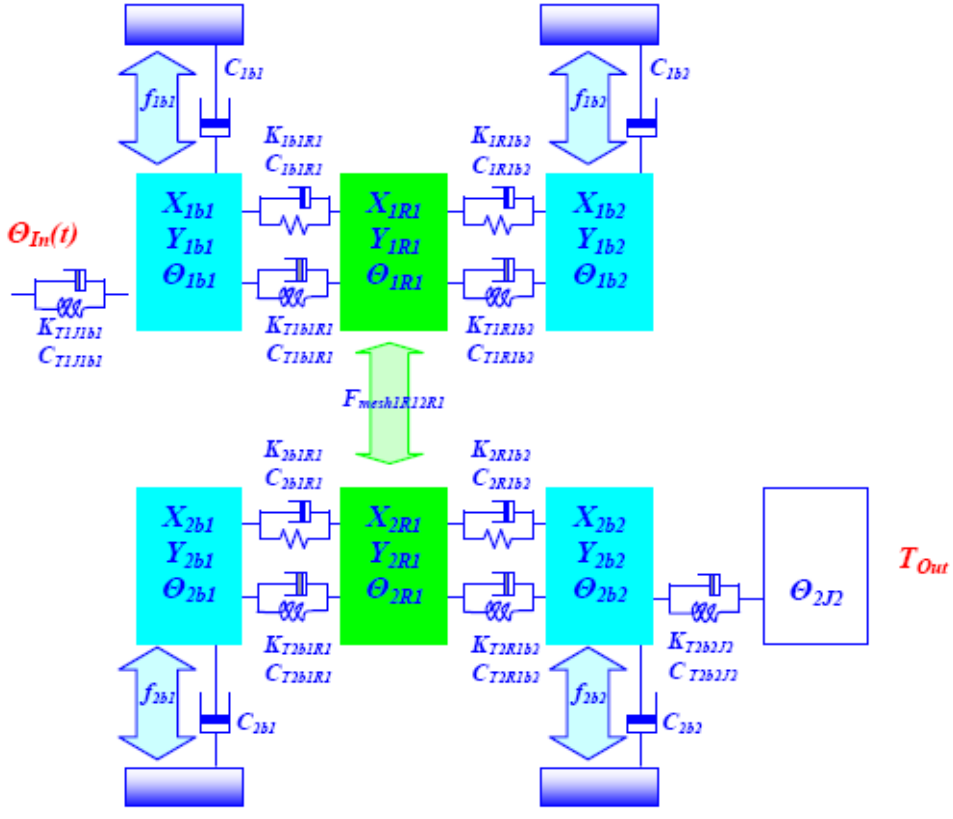

Fig. 1.- Scheme of the developed model 


\subsection{Index errors}

Although index errors are common and it is known their impact on gear dynamics, the number of researchers who propose numerical models for studying this phenomenon is sparse. In this work, index errors were added to the original model under the common assumption used by researchers to address gear profile deviations which generally considers that changes in the profiles are so small that the Line of Action (LOA) of the meshing contact forces does not change. In this way, there is only a reduction in the magnitude of the geometric overlap between the profiles of the teeth in contact in comparison with the ideal profiles $[11$, ¡Error! No se encuentra el origen de la referencia.].

Following this procedure the expression developed to obtain the geometrical separations between teeth profiles (see [2]) was modified according to (2) in order to include index errors

$\delta_{j}\left(\left\{\vec{r}_{1}, \theta_{1}\right\},\left\{\vec{r}_{2}, \theta_{2}\right\}\right)=u_{T j}\left(\left\{\vec{r}_{1}, \theta_{1}\right\}\left\{\vec{r}_{2}, \theta_{2}\right\}\{F\}\right)+e_{P j 1}^{L}\left(\theta_{1}\right)+e_{P j 2}^{L}\left(\theta_{2}\right)+e_{P j 1}^{R}\left(\theta_{1}\right)+e_{P j 2}^{R}\left(\theta_{2}\right)$

under the condition $F_{j} \geq 0 ; \quad j=1, \ldots n$

Where $\delta_{j}$ represents the geometrical separations between teeth profiles at potential contact $j$ (see Fig. 2) obtained for a certain position and rotation of gears (defined by vectors $r_{1}, r_{2}$ and angles $\theta_{1}, \theta_{2}$ ). On the right side, $u_{T j}$ represents the elastic deflection obtained at contact point $j$ under the force vector $F$ which is the unknown problem that was constrained by the complementarity condition in order to assure compressive contacts. Moreover, ePj1,2 are the index errors of pinion and wheel which were divided in these corresponding to the left (superscript $L$ ) and to the right flanks (superscript $R$ ) of each tooth.

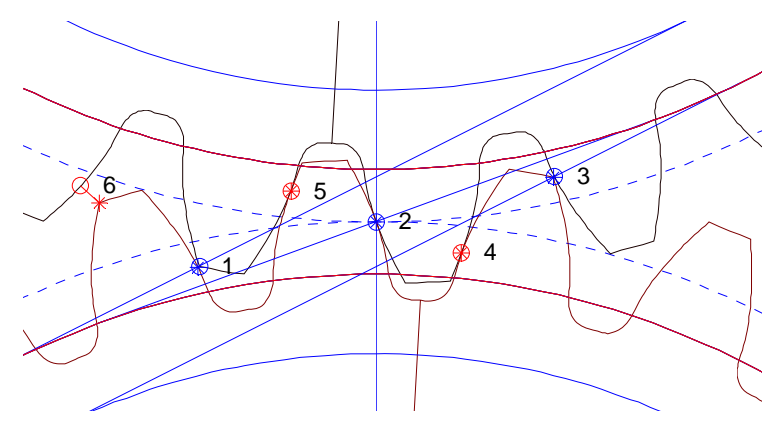

Fig. 2.- Example or considered potential contacts for calculation of geometrical overlaps

Index errors can be expressed as an angle or as a distance measured along the pitch line (see Fig. 3). In this work, the index errors were expressed in terms of distance above the pitch circle. The index error is different between wheels and is not periodic each meshing cycle (unlike the profile errors and reliefs). Thus, it is necessary to define the index error over the full rotation of the gear. Adopting a particular tooth as a reference for defining the accumulated index error, the error is discrete (one constant value for each flank) and periodic (with period $2 \pi$ ), so its value can be calculated in terms of the angle $\theta$ with respect to the reference tooth as the sum of $n$ harmonic functions of amplitude $A_{n}$ as

$$
e_{\text {pich }}(\theta)=\sum_{n=1}^{N} A_{n} \operatorname{sen}\left(n \cdot \text { floor }\left(\frac{\theta}{\theta_{p}}\right) \cdot \theta_{p}\right) ; \quad \theta_{p}=\frac{2 \pi}{Z}
$$


Where $\mathrm{Z}$ is the gear number of teeth and the floor function discretizes the harmonic function so that the particular index error for each tooth is determined. When the tooth used as a reference to measure the index error is not the contact tooth corresponding to the first angular position $\theta$ in (3), the angle should be modified including the corresponding phase deviation. Although in this paper the index error was considered periodic, in order to allow for comparison with run out, it is also possible to use other functions different from (3) so as to represent other kinds of errors like local pitch defects [9] or linear errors [8].

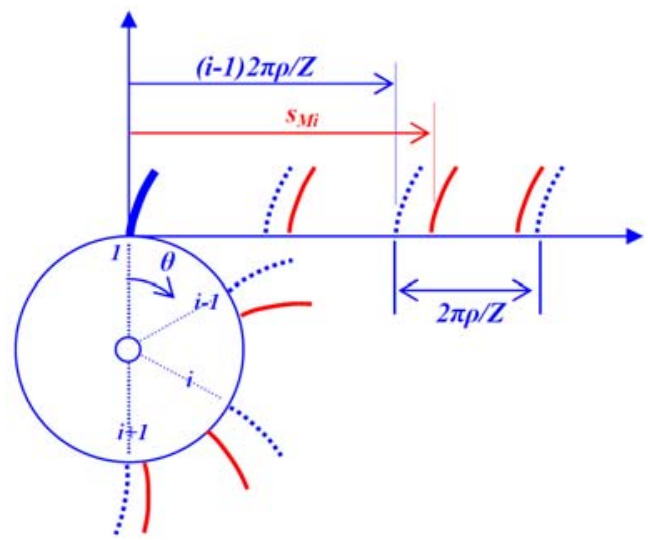

Fig. 3.- Index error definition

\subsection{Run out error}

Unlike index errors, eccentricity appears due to the displacement of the geometric center of the gear with respect to the center of rotation of the shaft on which it is mounted. The inclusion of this type of error leads to a modification of the line of action which affects the position where the teeth begin and finish the contact.

The eccentricity is introduced in the model by changing the position of the gear $i$ ( $i=$ $1,2)$ in expression (2) by (4), taking into account the magnitude of the eccentricity $e_{i}$ and its angular position with respect to the centers line $\theta_{e i}$ (according to the scheme presented in Fig. 4)

$$
\begin{aligned}
& x_{i e}=x_{i}+e_{i} \cos \left(\theta_{i}+\theta_{e i}\right) \\
& y_{i e}=y_{i}+e_{i} \cos \left(\theta_{i}+\theta_{e i}\right)
\end{aligned} \quad i=1,2
$$

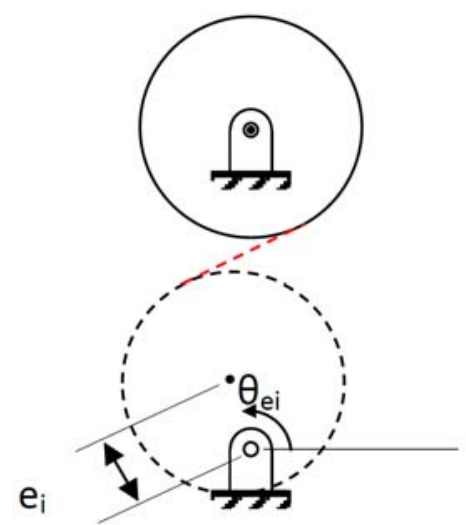




\section{Application example: quasi-static analysis.}

The proposed procedures for including index and run out errors were applied on the simulation of a single stage spur gear transmission supported by a couple of ball bearings. Data concerning gears were extracted from an experimental test bench described in literature (more details on ref. [7] and [2]) while a pair of 209 single-row radial deepgroove where considered as bearing model [13]. ¡Error! No se encuentra el origen de la referencia. summarizes the main features for each component. More details about necessary dynamic parameters to carry out dynamic simulations can be found in [5].

Table 1 Transmission data

\begin{tabular}{|c|c|c|c|}
\hline Parameter & Value & Parameter & Value \\
\hline \multicolumn{4}{|c|}{ Gear data } \\
\hline Number of teeth (gear $1 \& 2$ ) & 28 & Rack tip rounding & $0.25 \mathrm{~m}$ \\
\hline Module (m) & $3.175[\mathrm{~mm}]$ & Rack dedendum & $1 \mathbf{m}$ \\
\hline Elasticity Modulus & $210[\mathrm{GPa}]$ & Gear face width & $6.35[\mathrm{~mm}]$ \\
\hline Poisson's ratio & 0.3 & Gear shaft radius & $20[\mathrm{~mm}]$ \\
\hline Pressure angle & 20 [degree] & Gear tip rounding & $0.05 \mathrm{~m}$ \\
\hline Rack addendum & $1.25 \mathrm{~m}$ & Oil viscosity & $0.004(\mathrm{~Pa} \mathrm{~s})$ \\
\hline \multicolumn{4}{|c|}{ Bearing data } \\
\hline Contact stiffness & $1.210^{10}(\mathrm{~N} / \mathrm{m} 3 / 2)$ & Outer race diam. & $77.706(\mathrm{~mm})$ \\
\hline Ball diameter & $12.7(\mathrm{~mm})$ & Inner race diam. & $52.291(\mathrm{~mm})$ \\
\hline Number of balls & 9 & Inner groove rad & $6.6(\mathrm{~mm})$ \\
\hline Radial clearance & $15(\mu \mathrm{m})$ & Outer groove rad. & $6.6(\mathrm{~mm})$ \\
\hline \multicolumn{4}{|c|}{ Dynamic parameters } \\
\hline Output inertia & $3.5610^{-4}\left[\mathrm{Kg} \mathrm{m}^{2}\right]$ & Shaft flex. Stiff. & $6.2410^{8}[\mathrm{~N} / \mathrm{m}]$ \\
\hline Shaft Tor. Stiff. & $410^{5}[\mathrm{Nm} / \mathrm{rad}]$ & Coupling Stiff. & $4.010^{5}[\mathrm{Nm} / \mathrm{rad}]$ \\
\hline Shaft Tor. Damp. & $0[\mathrm{Nms} / \mathrm{rad}]$ & Coupling Damp. & $3.5761[\mathrm{Nms} / \mathrm{rad}]$ \\
\hline Shaft Flex. Damp. & $31.6[\mathrm{Ns} / \mathrm{m}]$ & Gear Mass & $0.7999[\mathrm{Kg}]$ \\
\hline Bearing Mass & $0.245[\mathrm{Kg}]$ & Gear Inertia & $4.010^{-4}\left[\mathrm{Kgm}^{2}\right]$ \\
\hline
\end{tabular}
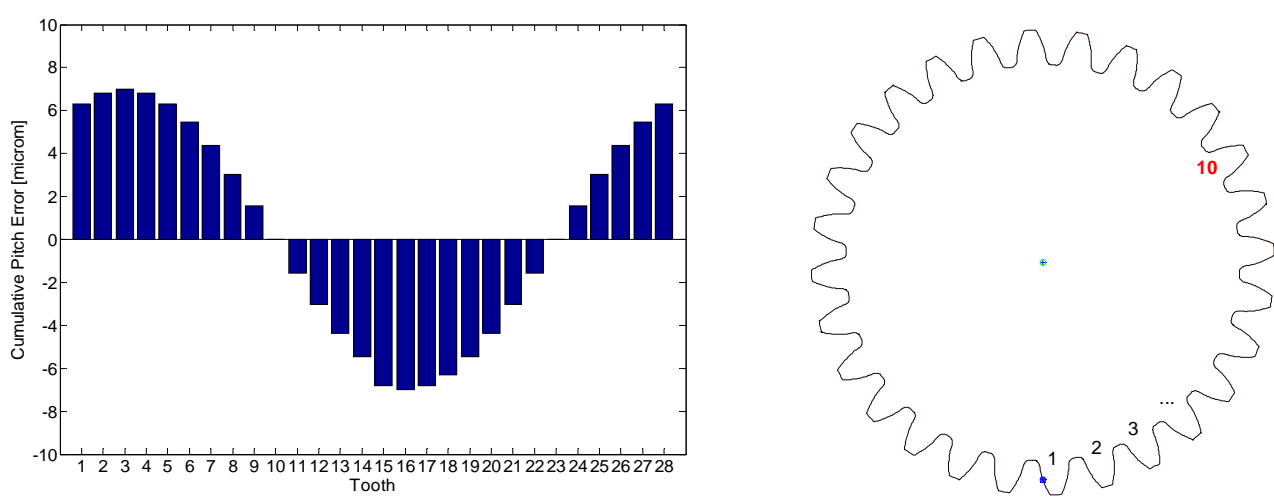

Fig. 5.- Cumulative index error for gear 1

Index error was only considered in gear 1, adopting a single harmonic with amplitude of $7 \mu \mathrm{m}$. Fig. 5 left, shows the index error considered in the simulations, that has been defined taking as reference the contact corresponding to the pitch point in tooth No. 10 
(see the amplitude is null for this tooth). However, initial conditions for dynamic simulations were defined such that the first contact takes place at the pitch point in tooth No. 1.

On the other hand, run out was modelled with an eccentricity value of $7 \mu \mathrm{m}$ and $270^{\circ}$ as angular position.
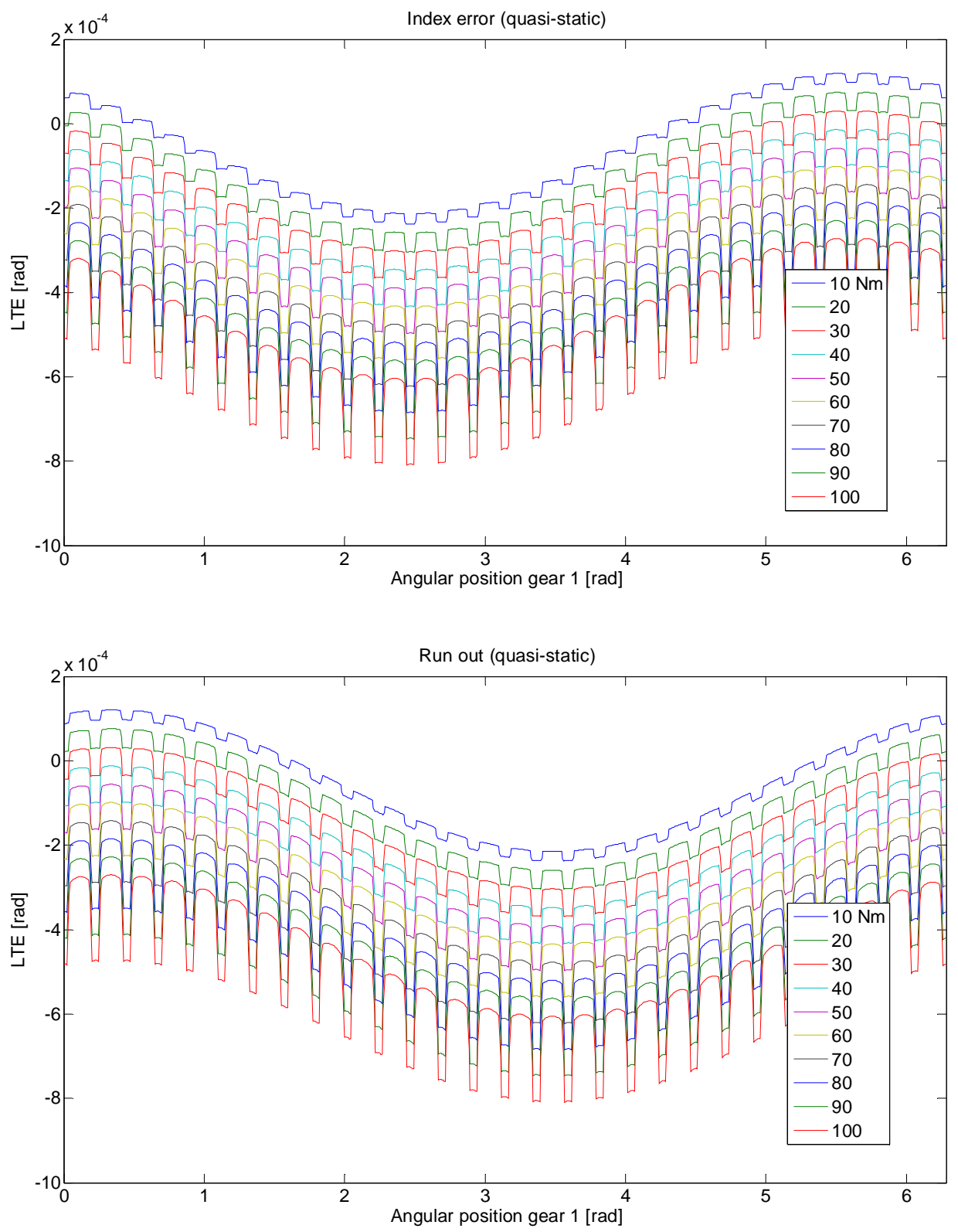

Fig. 6.- LTE under several torque loads: a) (Upper side) Index error in gear 1; b) (Lower side) Run out in gear 1.

In a first stage, quasi-static simulations were done considering only gear rotational dof under the assumption of rigid bearings. According Fig. 1, torque was applied at the output and then it was obtained the rotation angle at the input in order to find the equilibrium. Then, LTE is obtained applying equation (5)

$\operatorname{LTE}\left(\theta_{1}\right)=\theta_{1}-\frac{Z_{2}}{Z_{2}} \theta_{2}(5)$ 
Negative or positive values for LTE are derived from equation (5) depending on the sign of applied torque and rotation angle used for gear 1 in the simulations.

Moreover, LSR was calculated for the example transmission both in normal conditions as well as when index and run out errors were considered in simulations. For the sake of simplicity, in this paper only the LSR results are going to be presented. For more details about the procedure followed to obtain this feature, the reader is referred to the references [2] and [5].

With regard to LTE, both pitch and run out errors led to a once per turn superposed fluctuation

as

can be appreciated

in

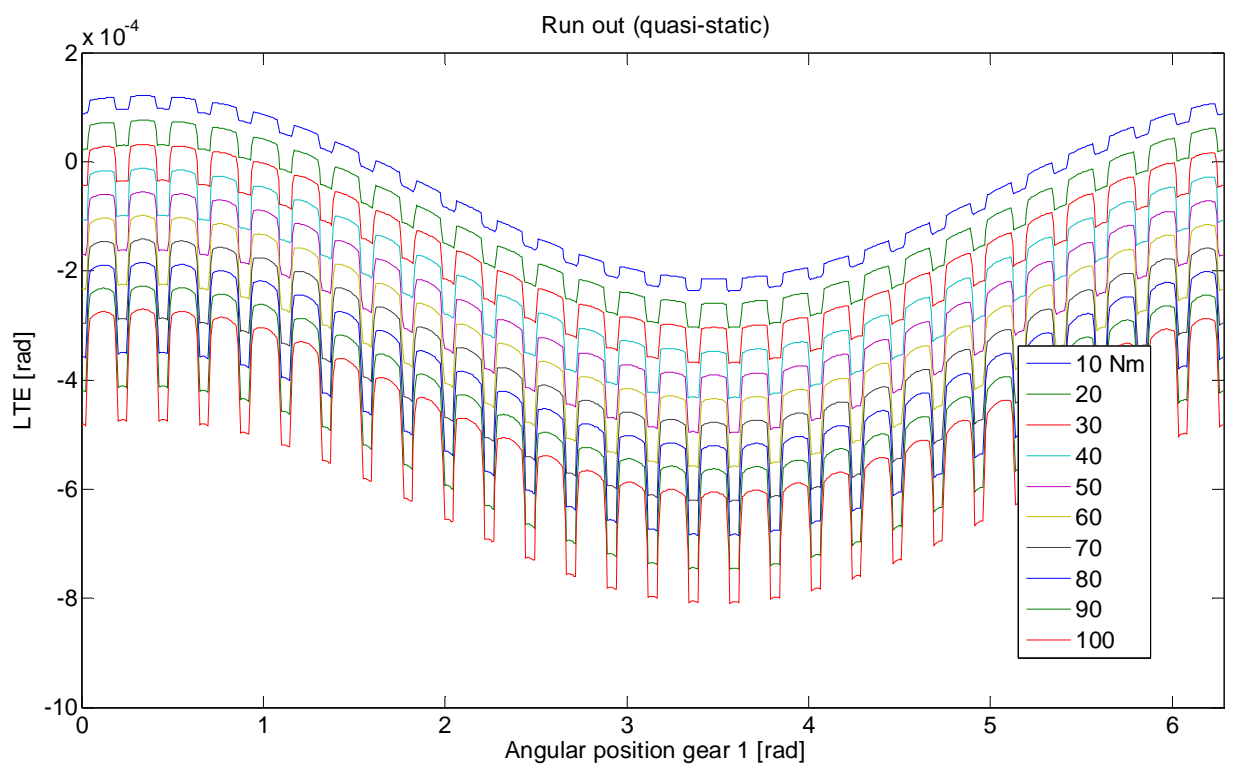

Fig. 6 a) and b) respectively (where it was considered that gear 1 rotates counterclockwise). Both errors provided a similar LTE as only one harmonic was considered for modelling index error and the amplitude of eccentricity was properly chosen for this purpose. 

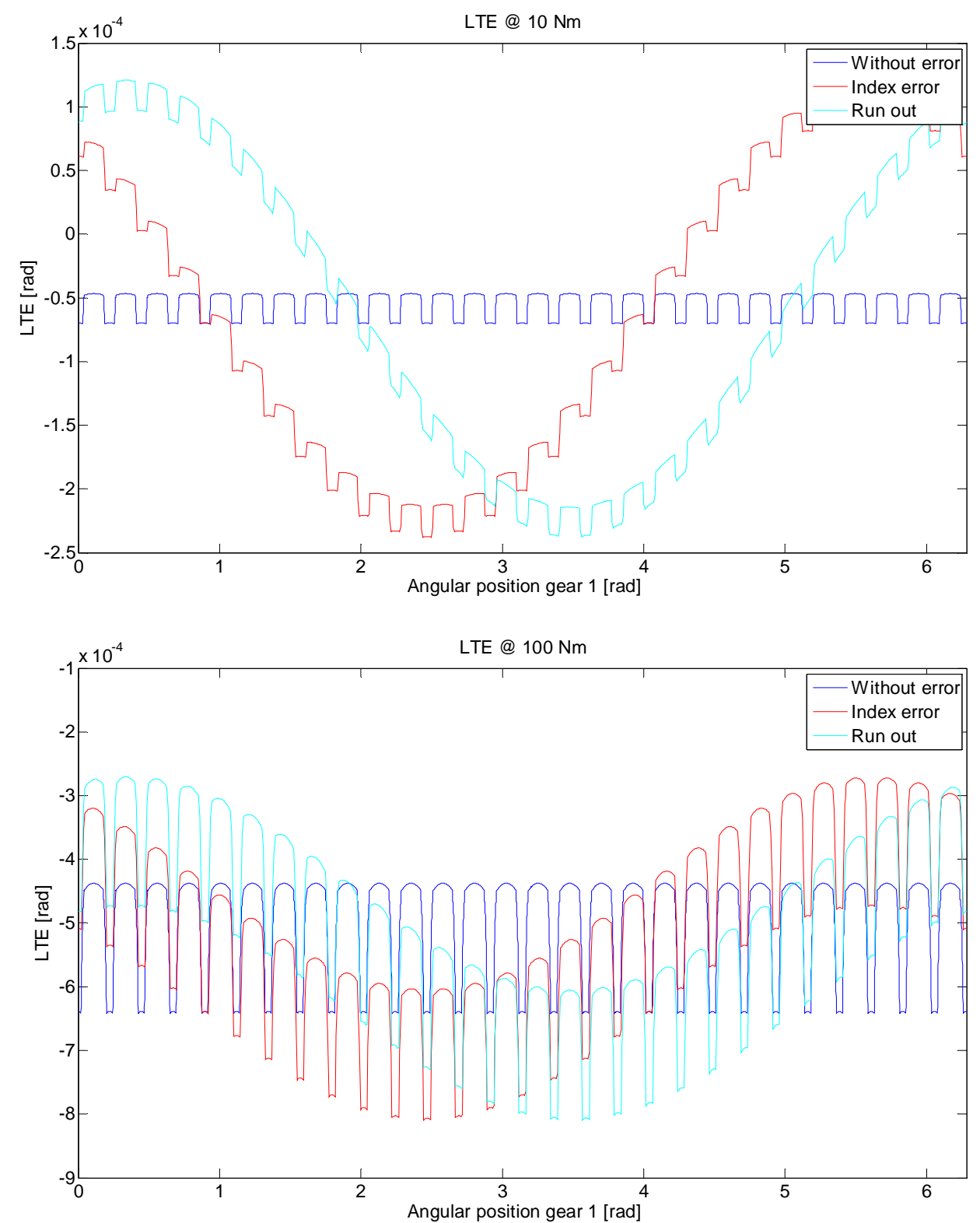

Fig. 7.- Comparison of LTE for normal conditions, Index and Run out errors in gear 1: a) (Upper) $10 \mathrm{Nm}$; b) (Lower) $100 \mathrm{Nm}$

However, a detailed error analysis enabled the observation of the discrete nature of the index error, which had a step-like shape, while the eccentricity showed a continuous variation 


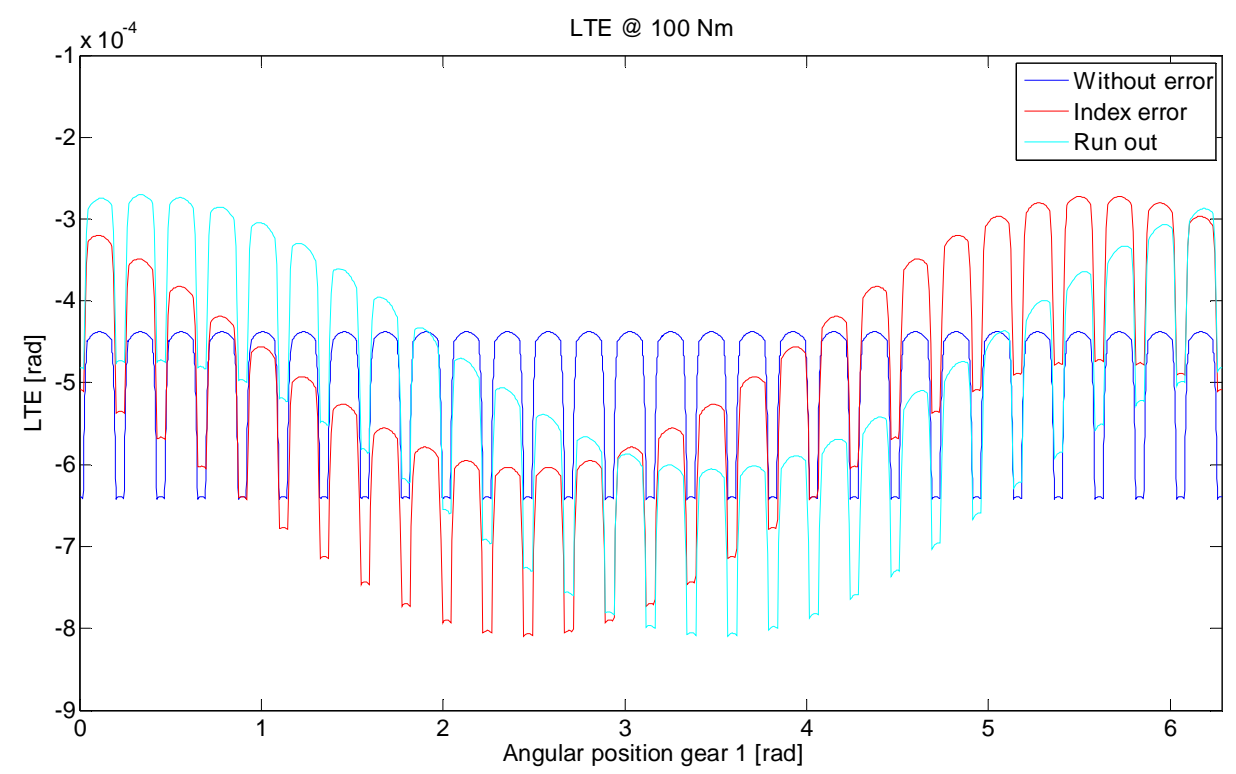

Fig. 7 a) and b)). The increase of the torque level trended to eliminate the differences between the two phenomena, yielding to similar results in both cases (see

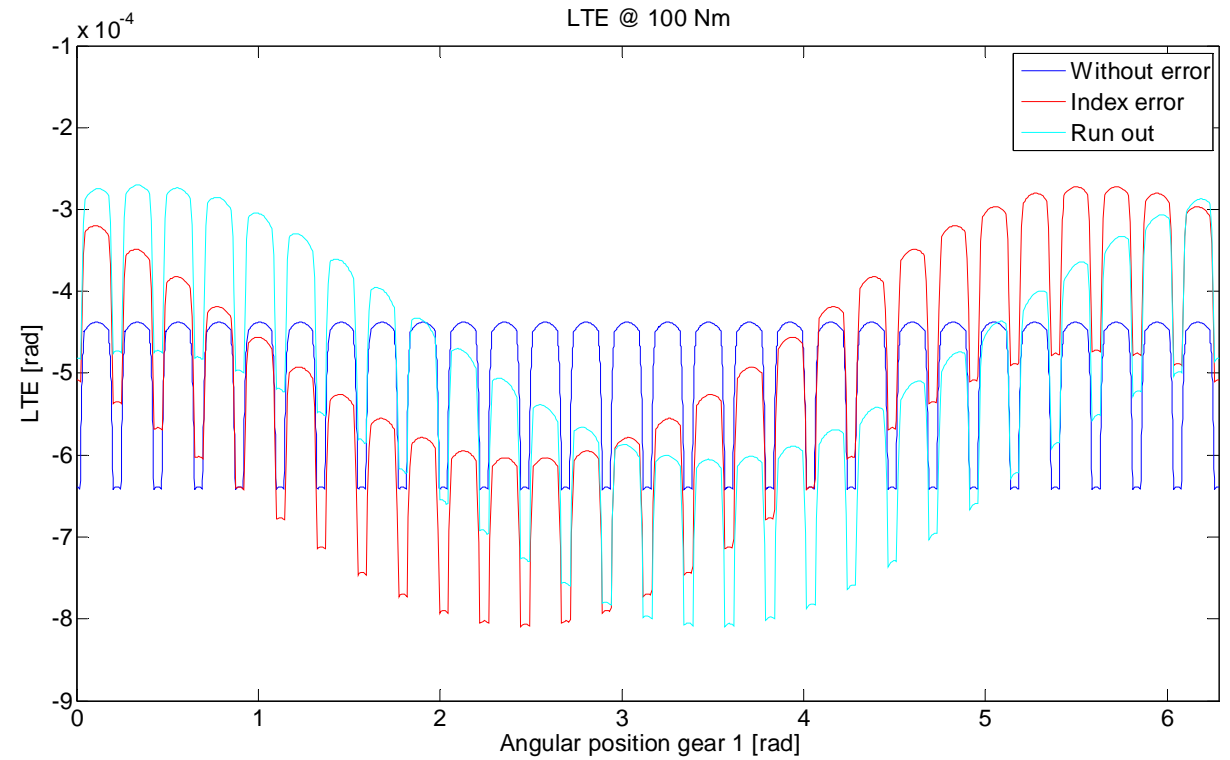

Fig. 7 b)).

The differences in LTE between index and run out were appreciated better in the frequency domain which is represented in Fig. 8 a) and b). Particularly in Fig. 8 a), when torque load was $10 \mathrm{Nm}$, it was observed that index error led to a clear increment of the frequency amplitude in the vicinity of gear mesh harmonics (multiples of $28^{\text {th }}$ gear order), while this behavior was less evident when run out was considered. Nevertheless, these differences were not so evident when torque increased up to $100 \mathrm{Nm}$ as can be appreciated Fig. $8 \mathrm{~b}$ ) where both index and run out provide similar resulting spectrums. 

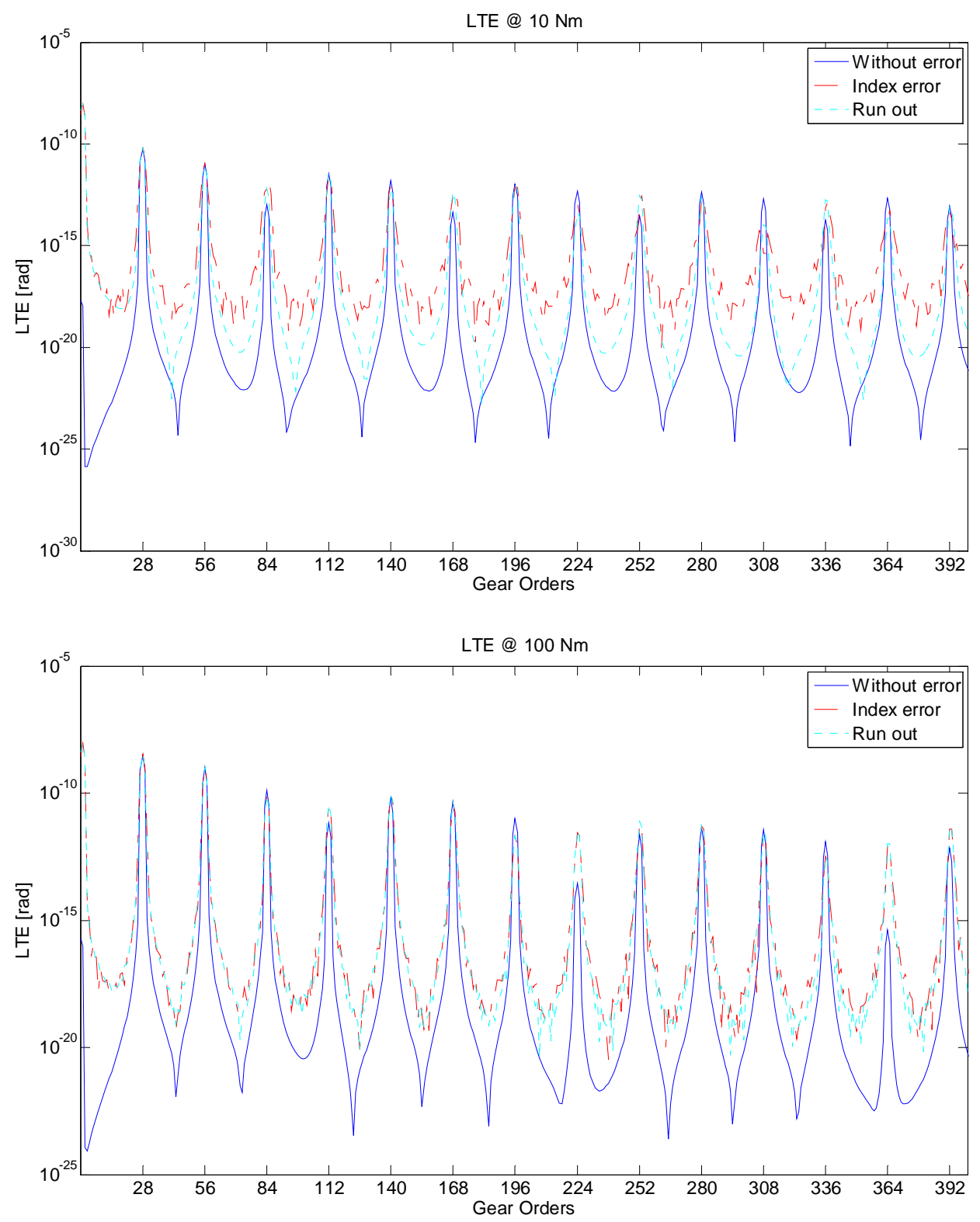

Fig. 8.- Comparison of LTE spectrum for Index and Run out errors in gear 1: a) (Upper side) 10 Nm; b) (Lower side) $100 \mathrm{Nm}$

A deeper analysis, having in mind the nature of each error, gave a better understanding of their consequences. Hence, whilst index error led to a change in the meshing starting and ending locations for each teeth couple as its angular position was modified, run out involved modifications of effective gear centers distance and therefore changes in effective pressure angle.

Thus, the differences between index and run out were clearer when the meshing forces were considered, particularly in the way they were shared between the teeth in contact. 


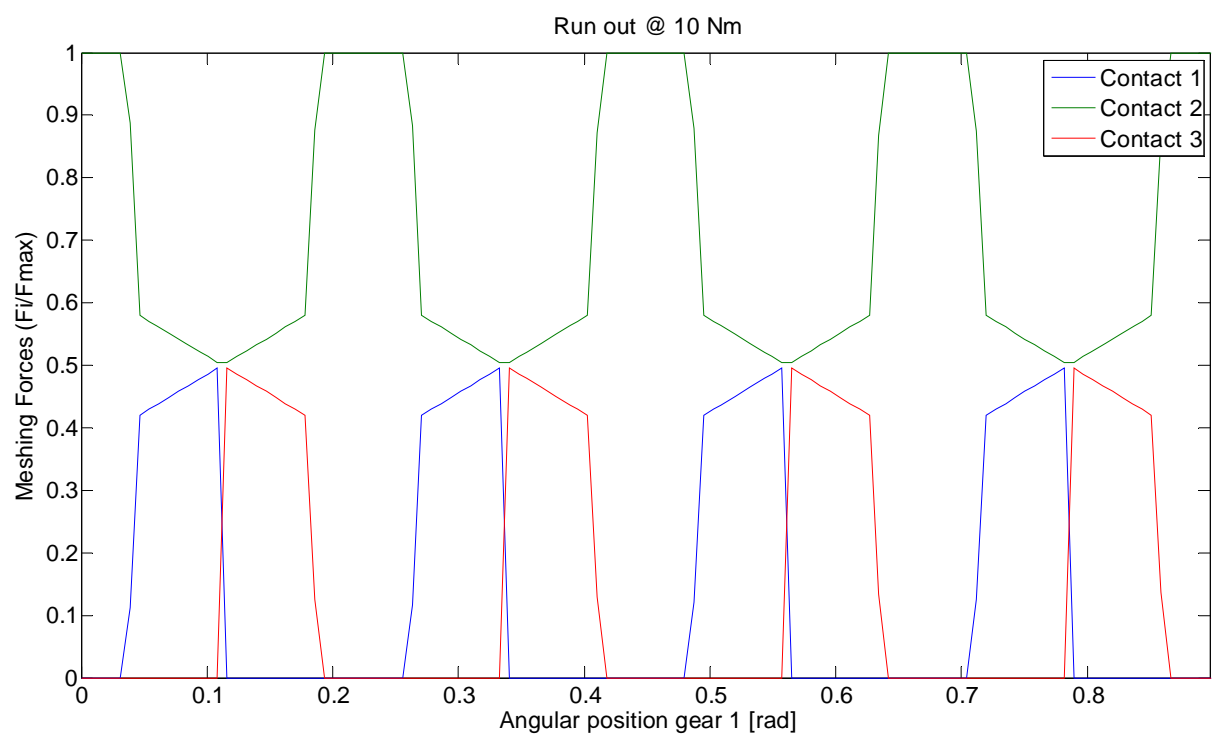

Fig. 9 and Fig. 10 shows the meshing forces (obtained from equation (2)) for each active contact over four meshing periods corresponding to two load conditions when index and run out errors were considered in simulations. As the magnitudes were normalized by the maximum value, this figure really shows the LSR for several meshing periods (see Fig. 2 to identify how the contacts were designated). When the transmitted torque was low, i. $\quad$ e. $\quad 10 \quad \mathrm{Nm}, \quad$ see

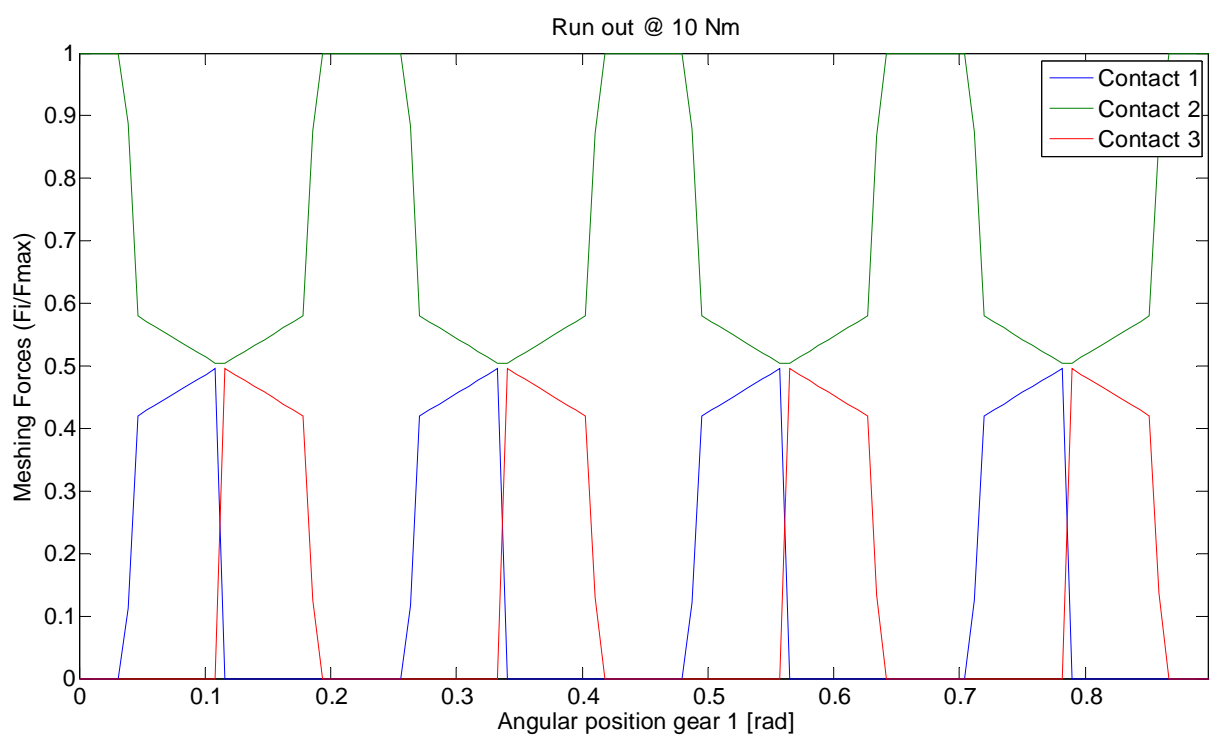

Fig. 9 a), the index errors led to an asymmetric shape, while the eccentricity did not change regarding the original one. As the transmitted torque increased $(100 \mathrm{Nm})$, the asymmetry for the index error LSR became less prominent but still appreciated (see ¡Error! No se encuentra el origen de la referencia.). As only the first harmonic was considered for the formulation of index errors, real situations could differ as several harmonics should have been included. Nonetheless, an asymmetric shape was expected for the LSR, as demonstrated in this simplified example. Because, in general, when transmissions with different numbers of gear teeth are considered, the LSR is asymmetric by nature. Moreover, in these cases, index errors affected the shape of the LSR over a fundamental period of each meshing gear but also the hunting periods were important to consider. As a consequence, complex interactions between gear indexing errors could be expected, affecting the transmission dynamics and therefore its life expectancy lead- 
ing to dangerous situations involving severe overloads and even contact loss in certain operation conditions. [9].
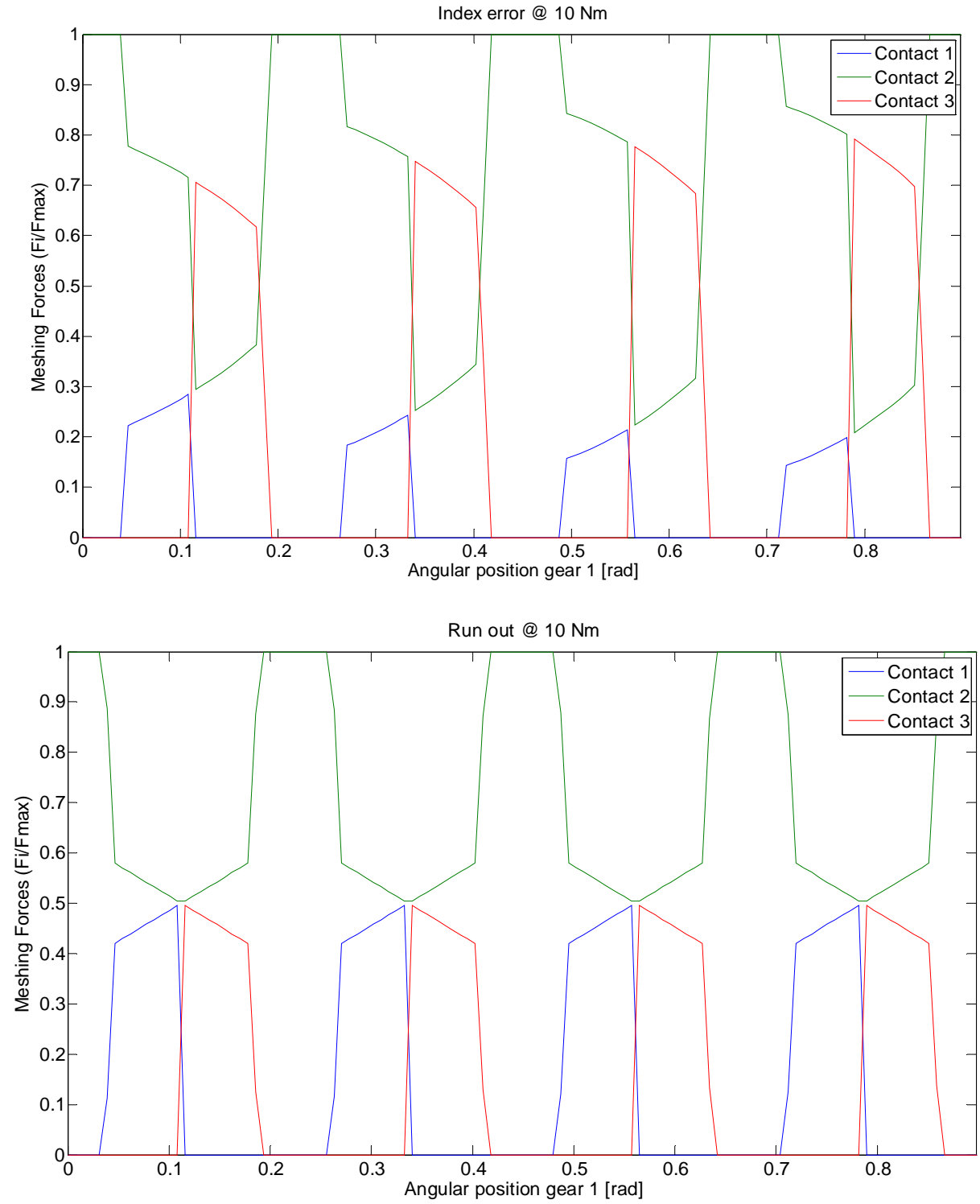

Fig. 9.- Normalized meshing forces @ 10 Nm a) (upper) Index errors; b) (lower) Run out 

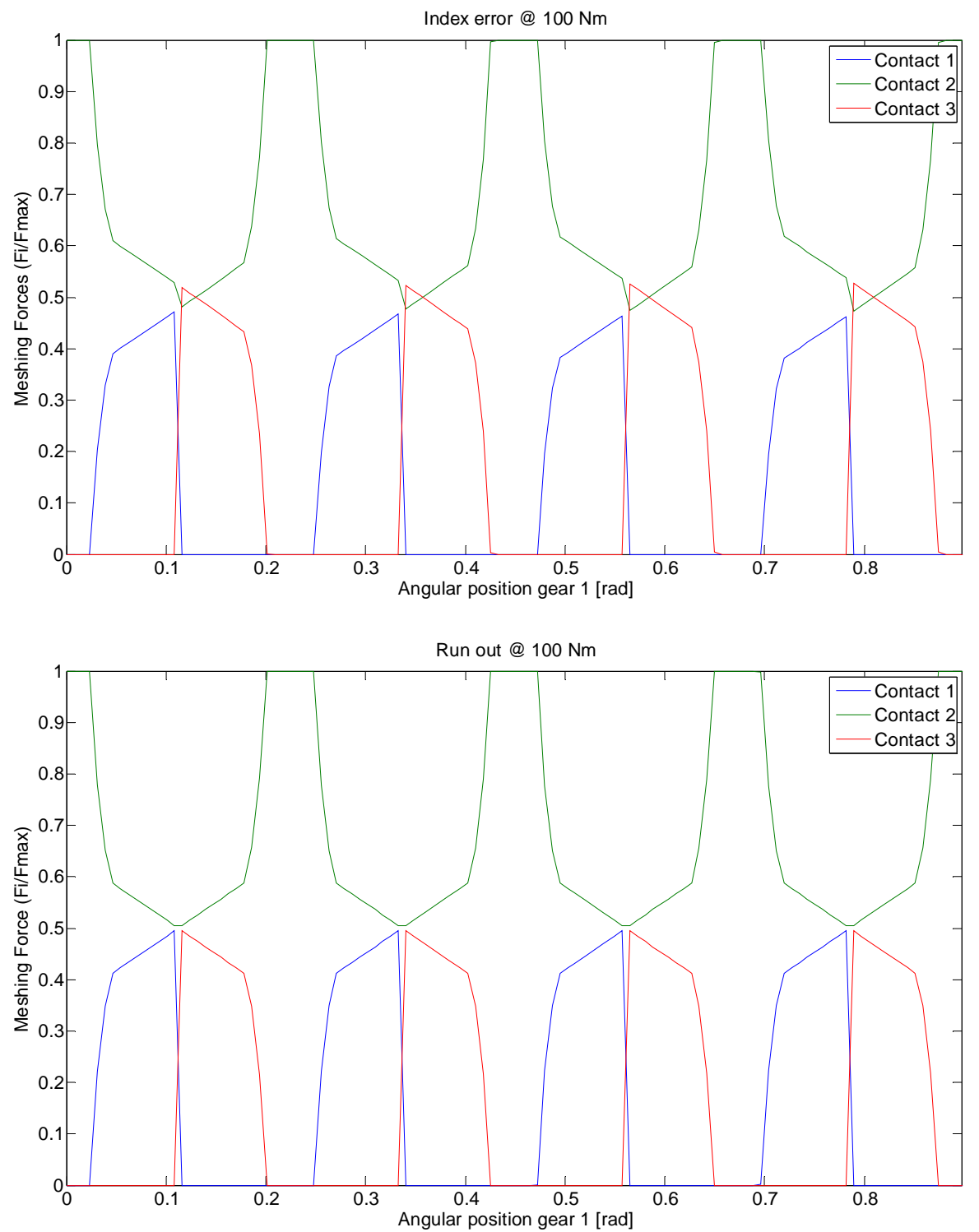

Fig. 10.- Normalized meshing forces @ 100 Nm a) (upper) Index errors; b) (lower) Run out

In contrast to index errors, run out did not lead to changes in the LSR but results in modifications of the resultant LOA were obtained, as can be appreciated in Fig. 11, where the error magnitude is deliberately exaggerated in order to facilitate the understanding.

As consequence, run out errors led to fluctuations in the effective pressure angle along a gear turn as can be appreciated in 


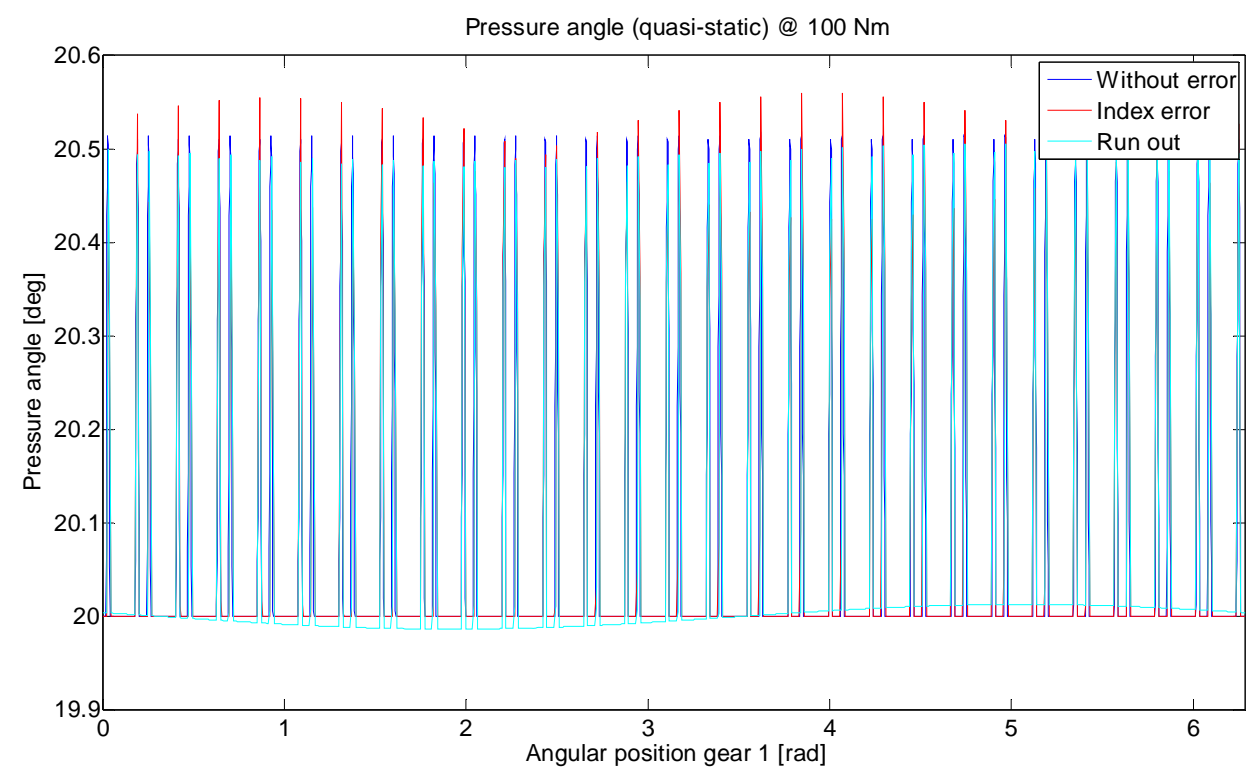

Fig. 12. This fluctuation was identified clearly a once per turn variation of the pressure angle when run out was considered in simulations. Moreover, the reader should be aware about the sudden changes in the pressure angle which appeared at certain angular locations. These peaks corresponded with contacts in the tip rounding arc considered at the top of the teeth in order to avoid corner contacts which resulted in forces out of the nominal LOA and therefore in instantaneous changes in the effective pressure angle. The amplitude of these peaks was modulated when index errors were considered due to the changes in the angular location of the teeth. Once more, higher transmitted torques masked the effect and complicated the identification of the modulation due to index errors while run out was still clearly appreciated

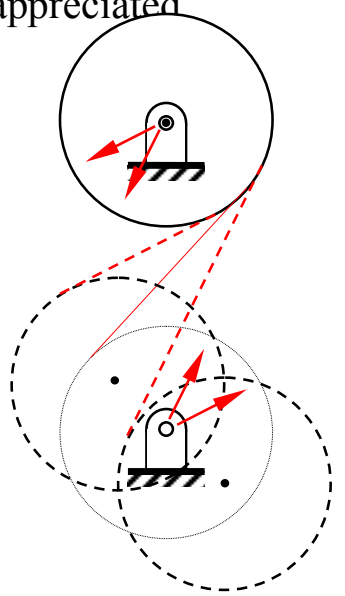

Fig. 11.- Scheme of the LOA direction changes due to Run out. 

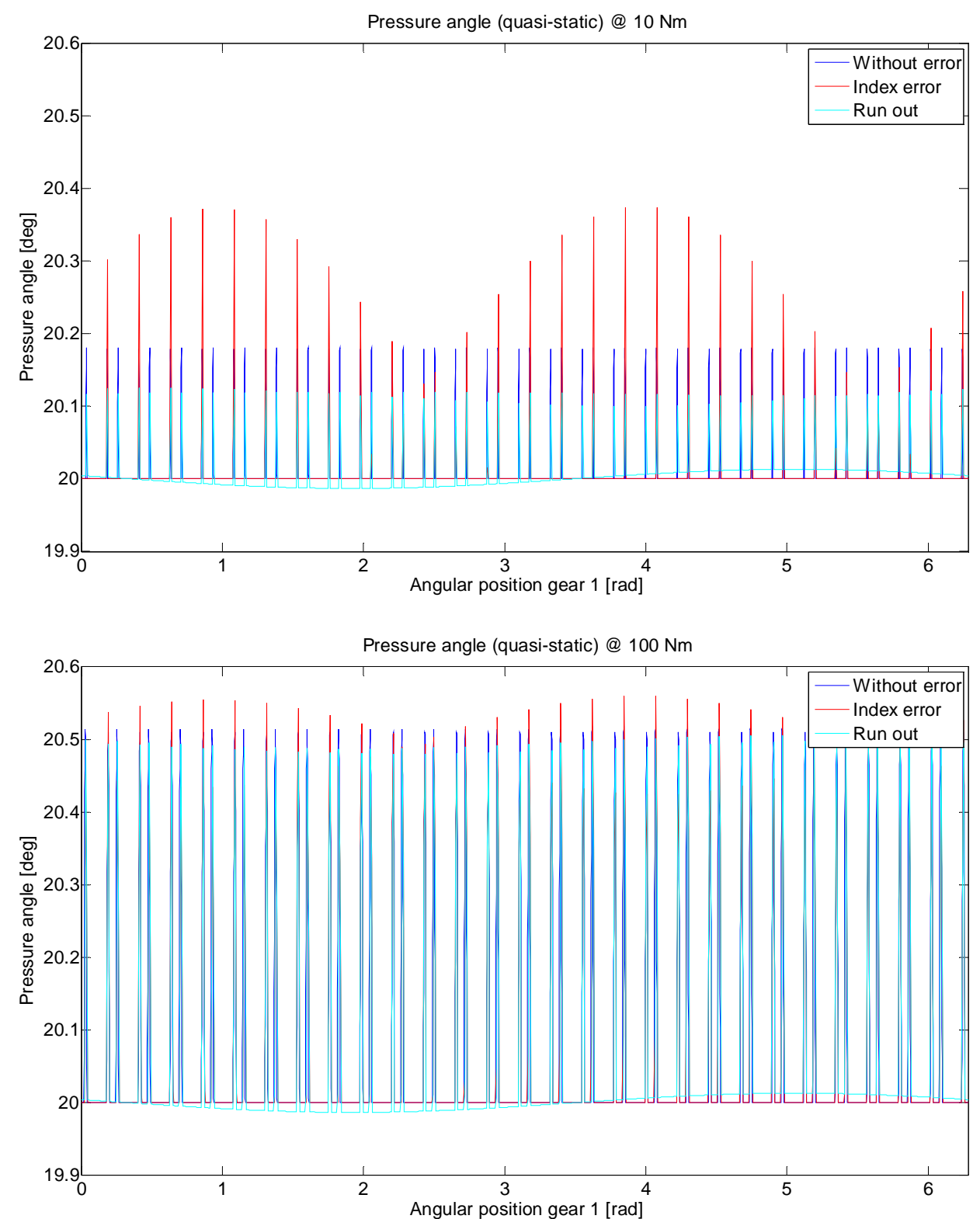

Fig. 12.- Comparison of effective pressure angle for normal conditions, Index and Run out errors in gear 1 (quasi-static) a) (Upper) $10 \mathrm{Nm}$; b) (Lower) $100 \mathrm{Nm}$.

\section{Dynamic simulations.}

In a second stage, dynamic simulations were carried out considering a (negative or counterclockwise) rotational speed of $1000 \mathrm{rpm}$ and several loads. Dynamic equations were implemented in Simulink environment and integrated by a fixed step solver (ODE 3 Bogacki-Shampine) using a sampling frequency of $75 \mathrm{kHz}$. In contrast with quasistatic studies, dynamic simulations were performed considering the effect of variable bearing compliance. Initial position for gears and bearings was obtained by a previous quasi-static calculation considering contact in the pitch point of tooth number 1 (see Fig. 5) in order to reduce the transient period. 

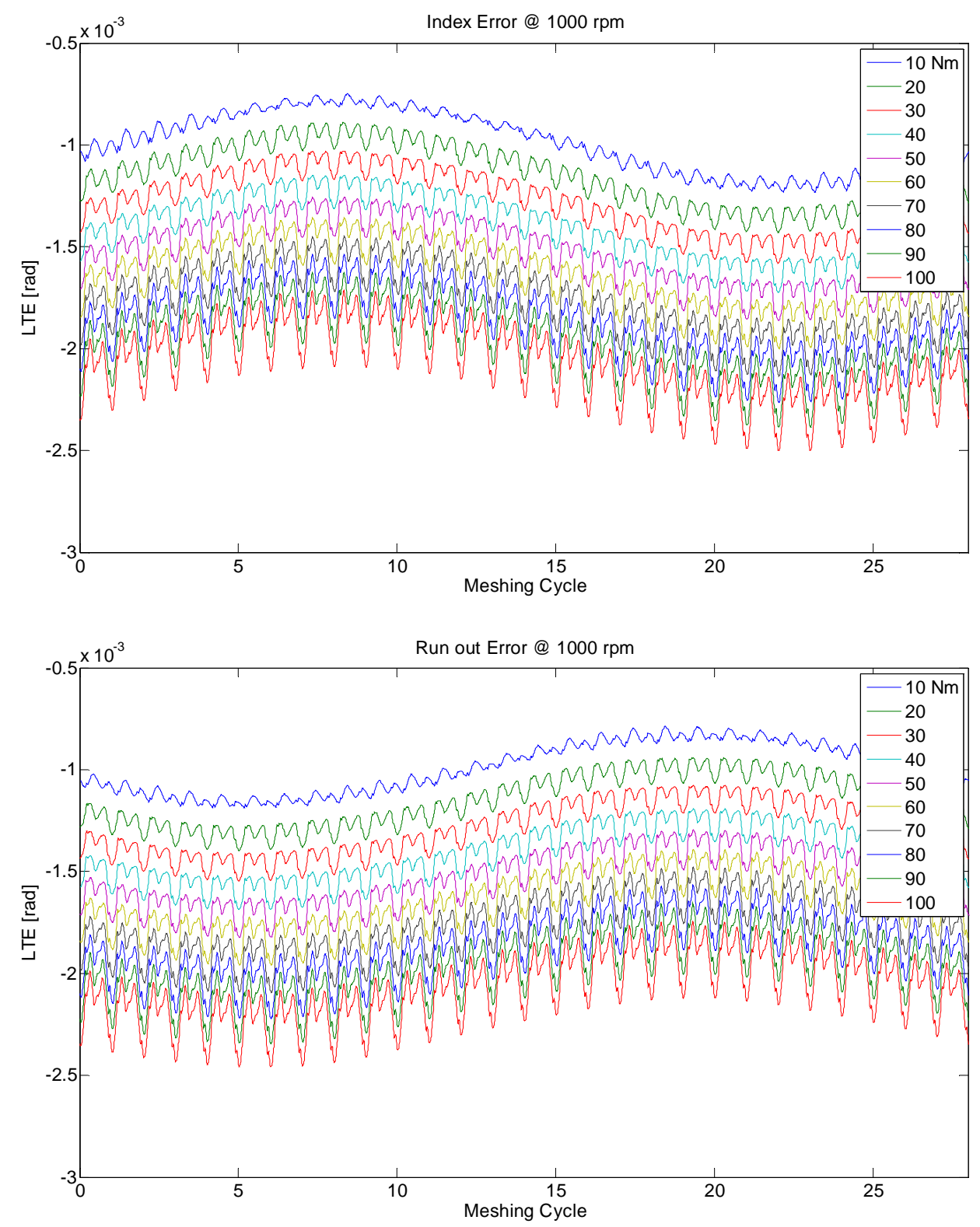

Fig. 13.- LTE under several torque loads @ 1000 rpm: a) (Upper side) Index error in gear 1 and gear 2; b) (Lower side) Run out on gear 1

In dynamic simulations, index error was included in both gears considering only one harmonic with amplitude of $7 \mu \mathrm{m}$ for gear 1 and $5 \mu \mathrm{m}$ for gear 2 . In both gears, tooth number 10 was used as reference but with a phase delay of 180 degrees in gear 2 . Regarding run out, the same values used for quasi-static analysis were considered. LTE obtained in dynamic simulations Fig. 13 followed a similar pattern than in static analysis as presented in Fig. 6. At this respect, the reader should have in mind that dynamic simulations were done considering clockwise rotation for gear 1 .

Nevertheless, in this case and unlike the quasi-static calculations it was not possible to discern what the origin of the LTE fluctuation is, even if transmitted torque is the lowest. 

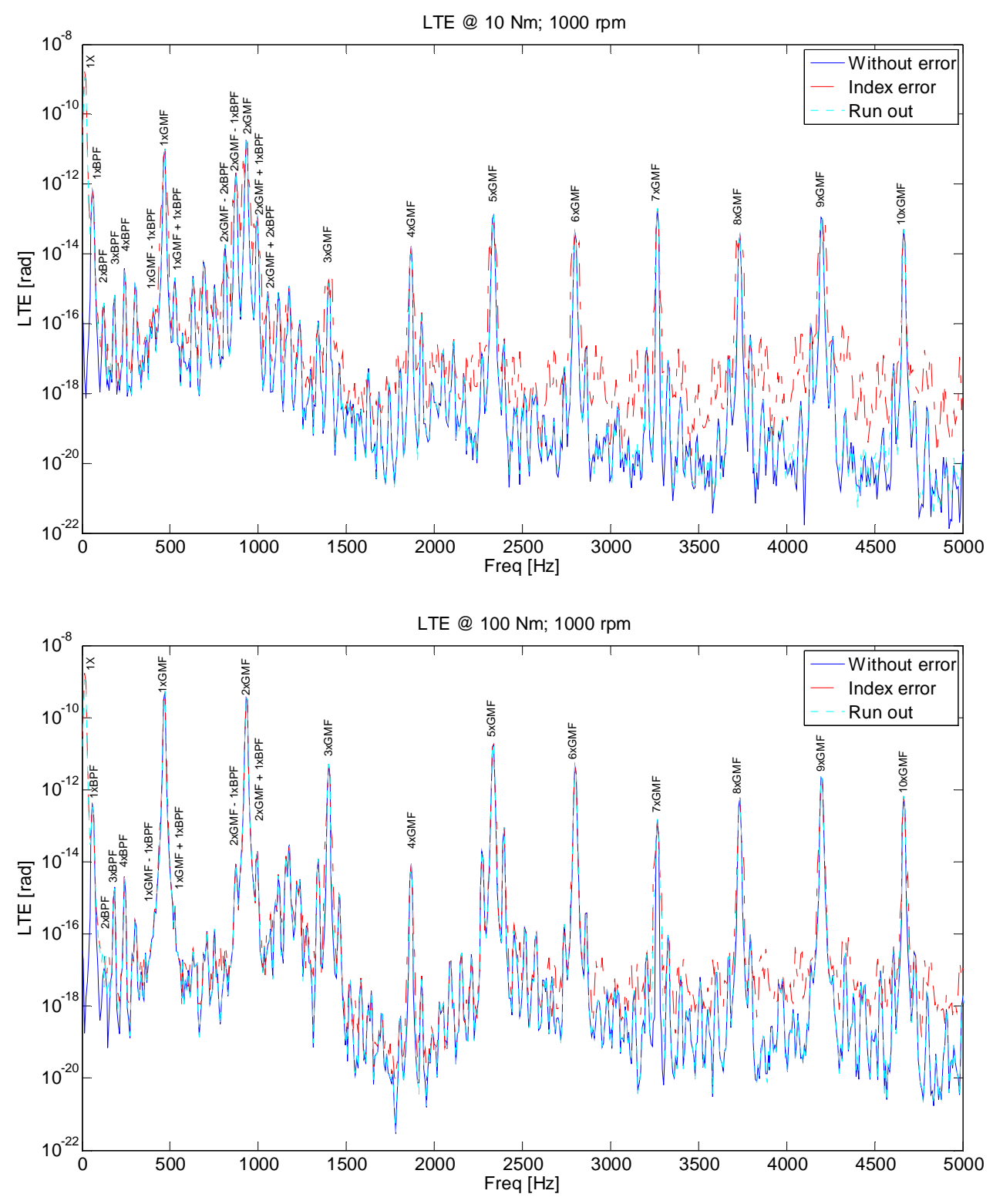

Fig. 14.- Comparison of LTE spectrum without errors and with Index and Run out errors: a) (Upper side) 1000 rpm @ 10 Nm; b) (Lower side) 1000 rpm @ 100 Nm

On the other hand, the index and run out roles were clearer in the frequency domain and therefore some differences were observed. For the sake of clarity, in Fig. 14 only the spectra corresponding to the minimum and maximum torque of the simulations carried out is presented. In contrast with the quasi-static simulations (where variable bearing compliance was not considered), additional peaks were identified in the low frequency range due to the bearing Ball Pass Frequency (BPF) which also modulated the LTE resulting in lateral side bands around the Gear Mesh Frequency (GMF) harmonics. At this point the reader should realize that practical identification of BPF frequencies in the low frequency region is hardly possible due to unavoidable noise involved in experimental measurements.

With regard to the differences between the consequences of each kind of error, index errors resulted in a slight modulation around the GMF harmonics at the shaft rotation frequency which is not properly seen in the figure due to the reduced spectra resolution. 
Nonetheless, run out seems to be less evident, although certain modulation were observed around some harmonics (i.e. the $7^{\text {th }}, 8^{\text {th }}$ and $9^{\text {th }}$ ). When torque increased, the modulation due to index errors was observed in the high order GMF harmonics, becoming less evident in the low frequency region, while run out did not seem to have consequences. However, slight changes were still observed for example around the $7^{\text {th }}$ GMF harmonic

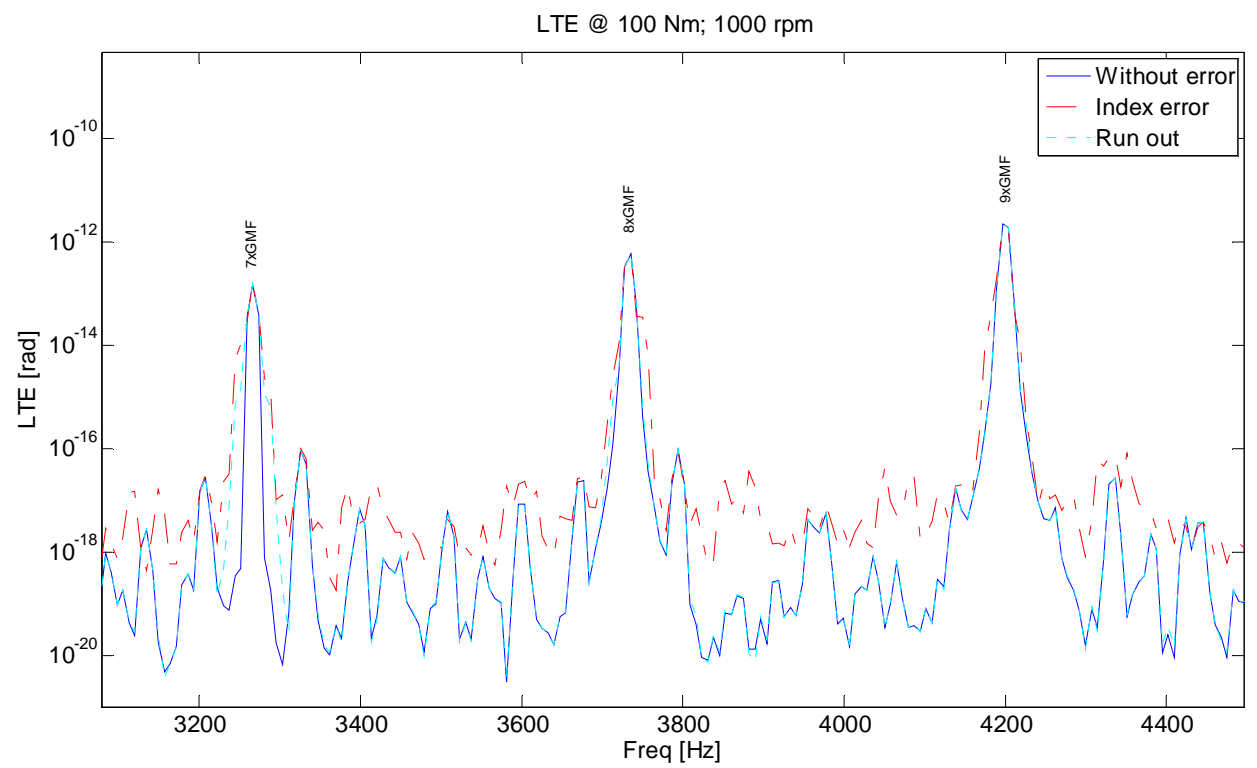

Fig. 15. 

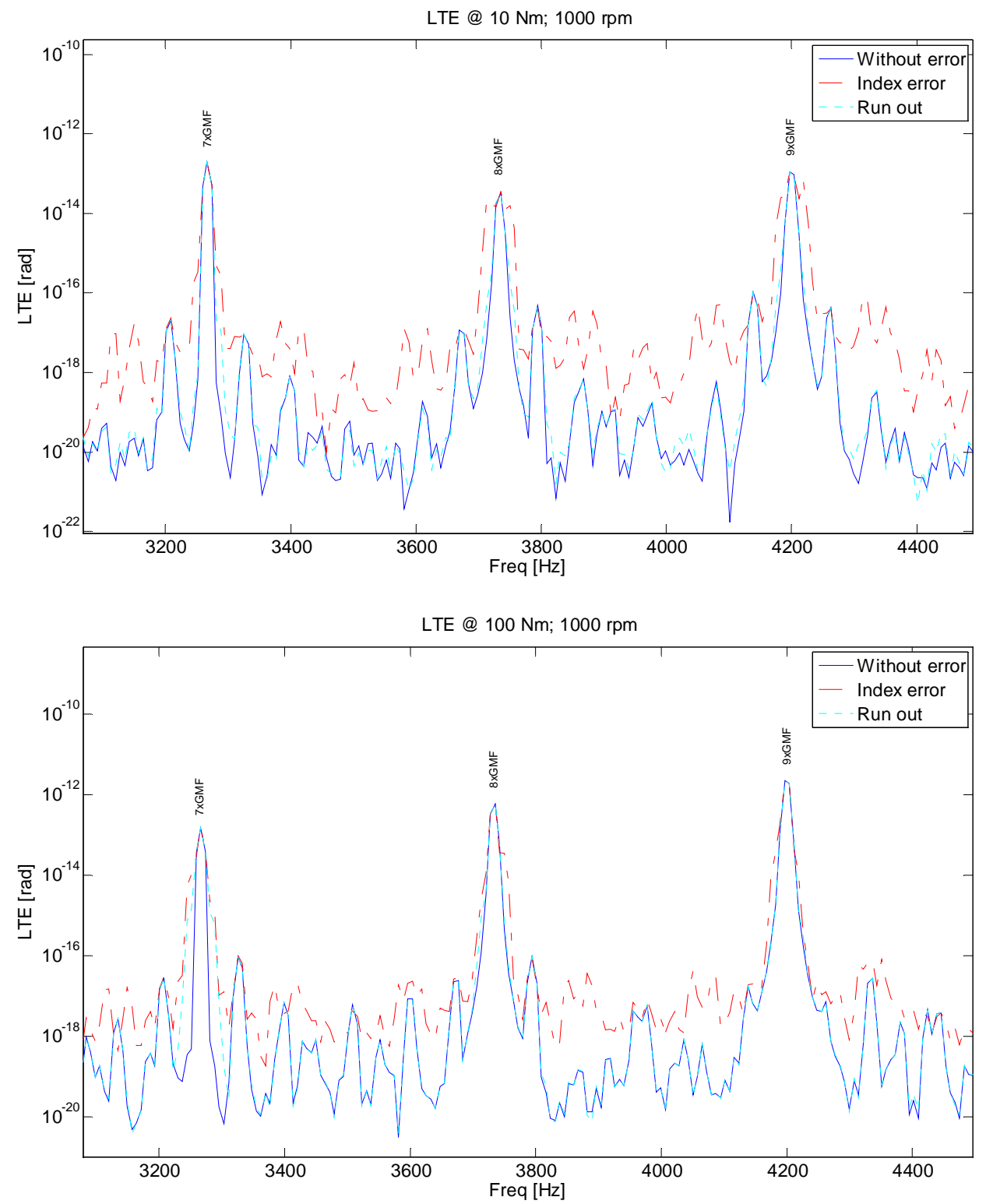

Fig. 15.- Comparison of LTE spectrum for Index and Run out errors (detail from the 7th to the 9th GMF harmonic) a) (Upper side) 1000 rpm @ 10 Nm; b) (Lower side) 1000 rpm @ 100 Nm 
As

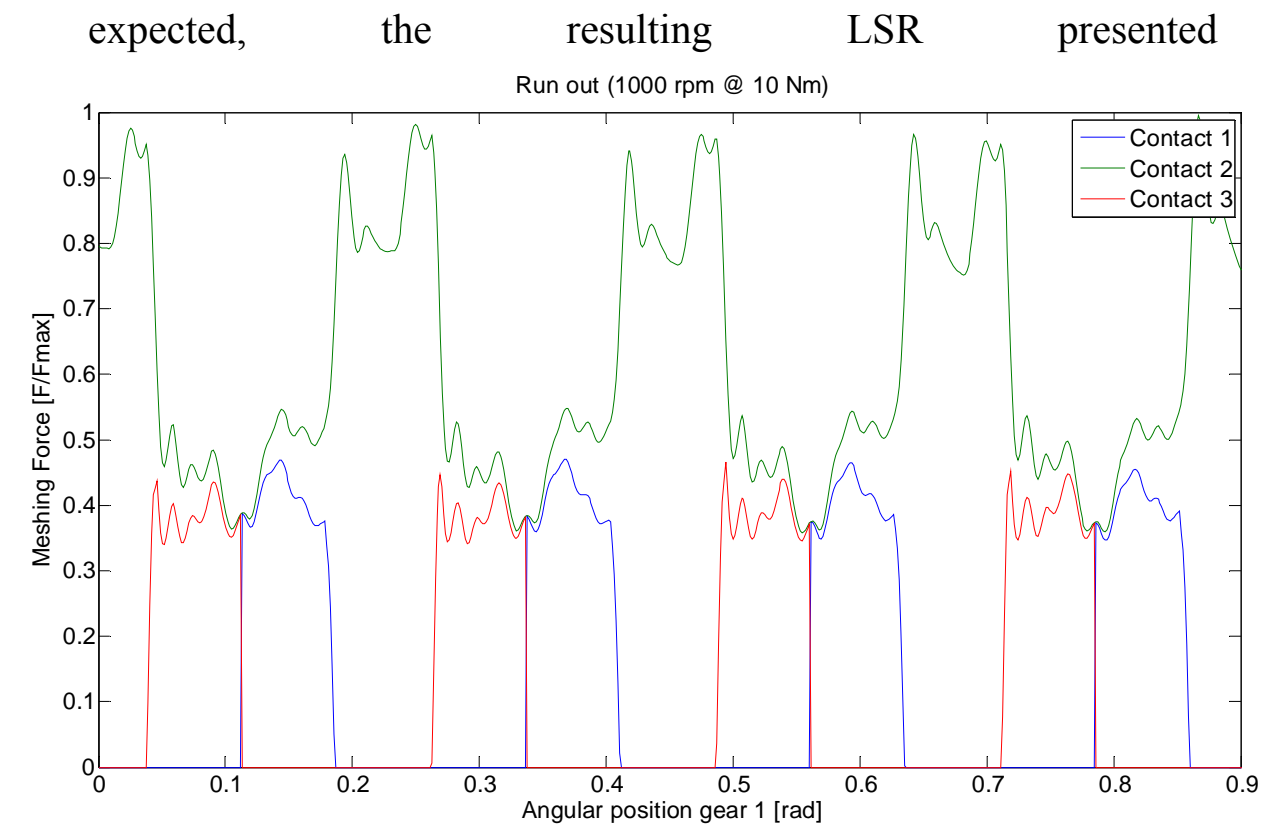

Fig.

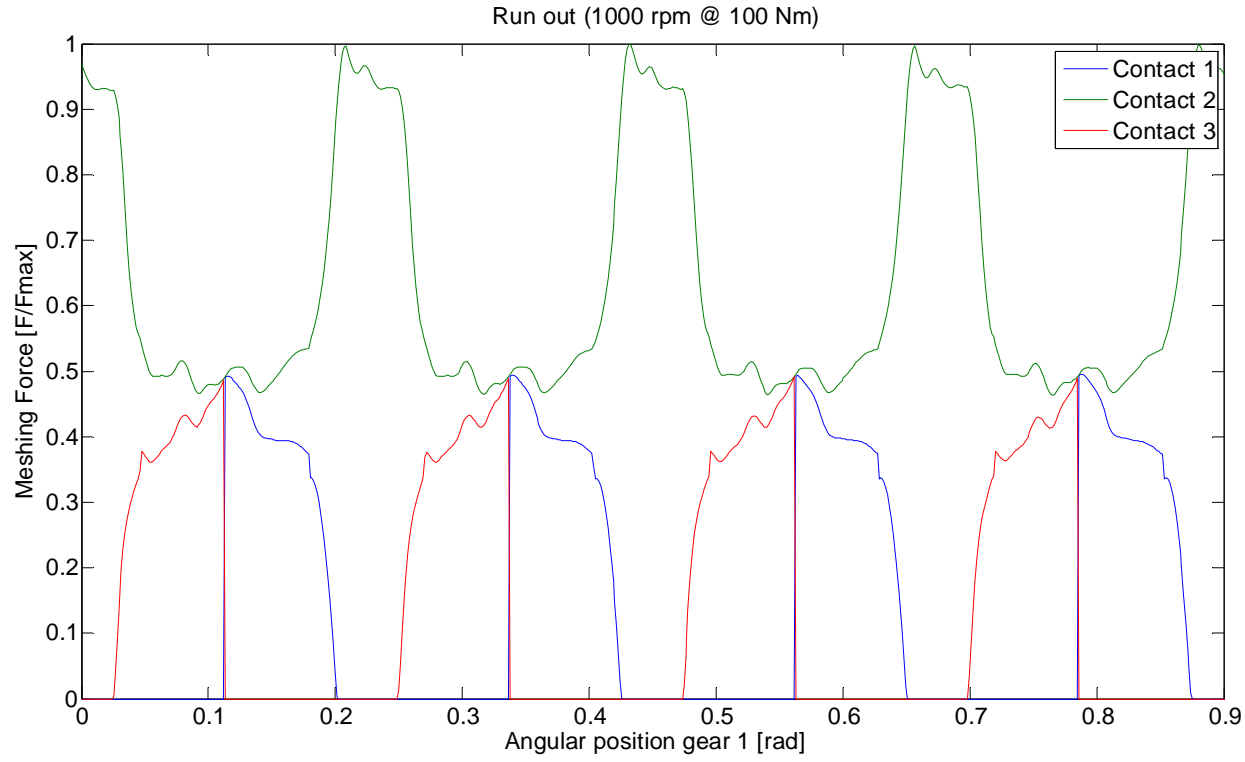

Fig. 17 became asymmetric when index errors were considered, particularly for low transmitted torque. The reader should be aware that the sequence of contacts seemed to be different from the quasi-static results presented in 


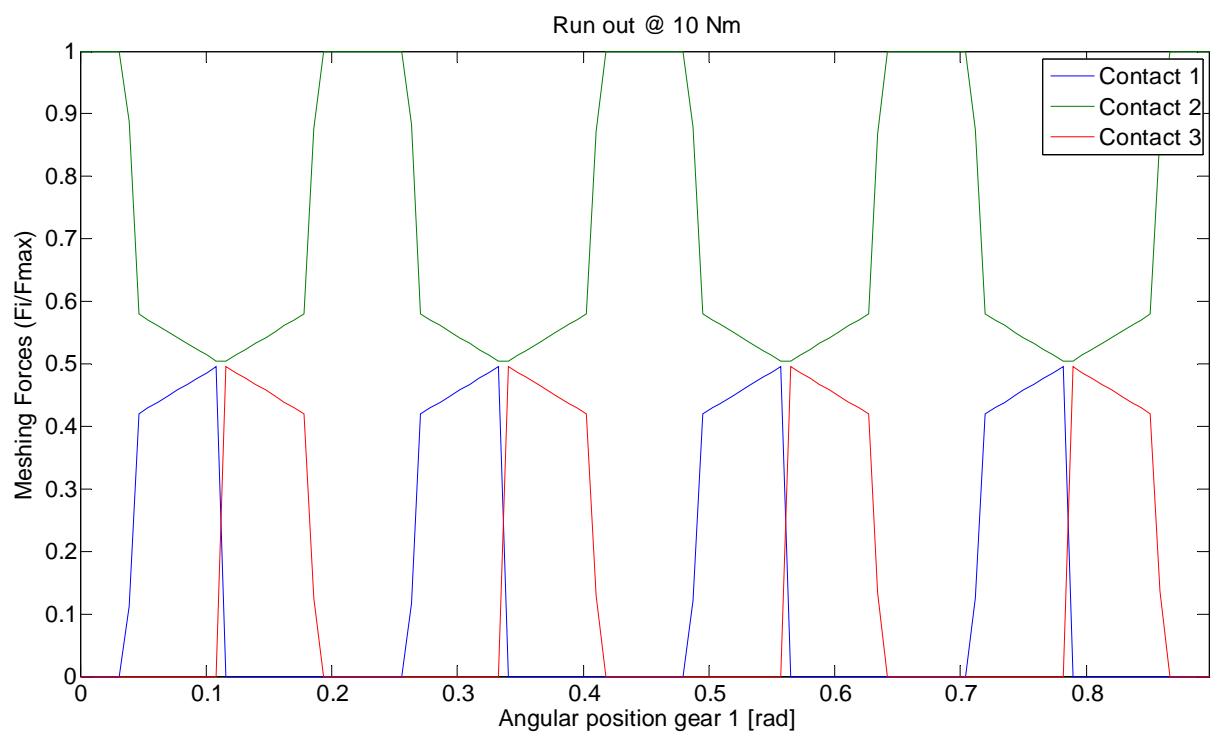

$\mathrm{F}$

ig. 9 and Fig. 10. This is due to the fact that dynamic simulations were carried out considering a negative value (clockwise) of rotational speed in gear 1, whilst for the sake of clarity, the absolute value of the angle was taken in

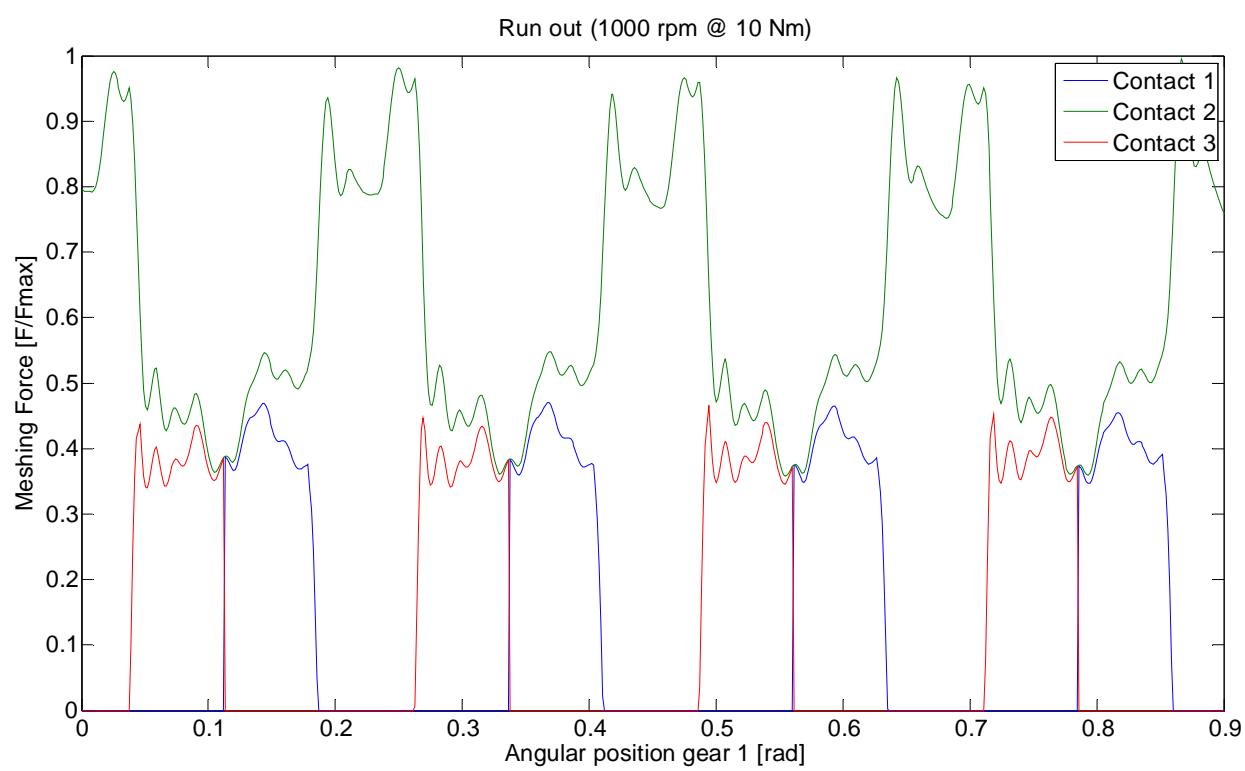

Fig. 


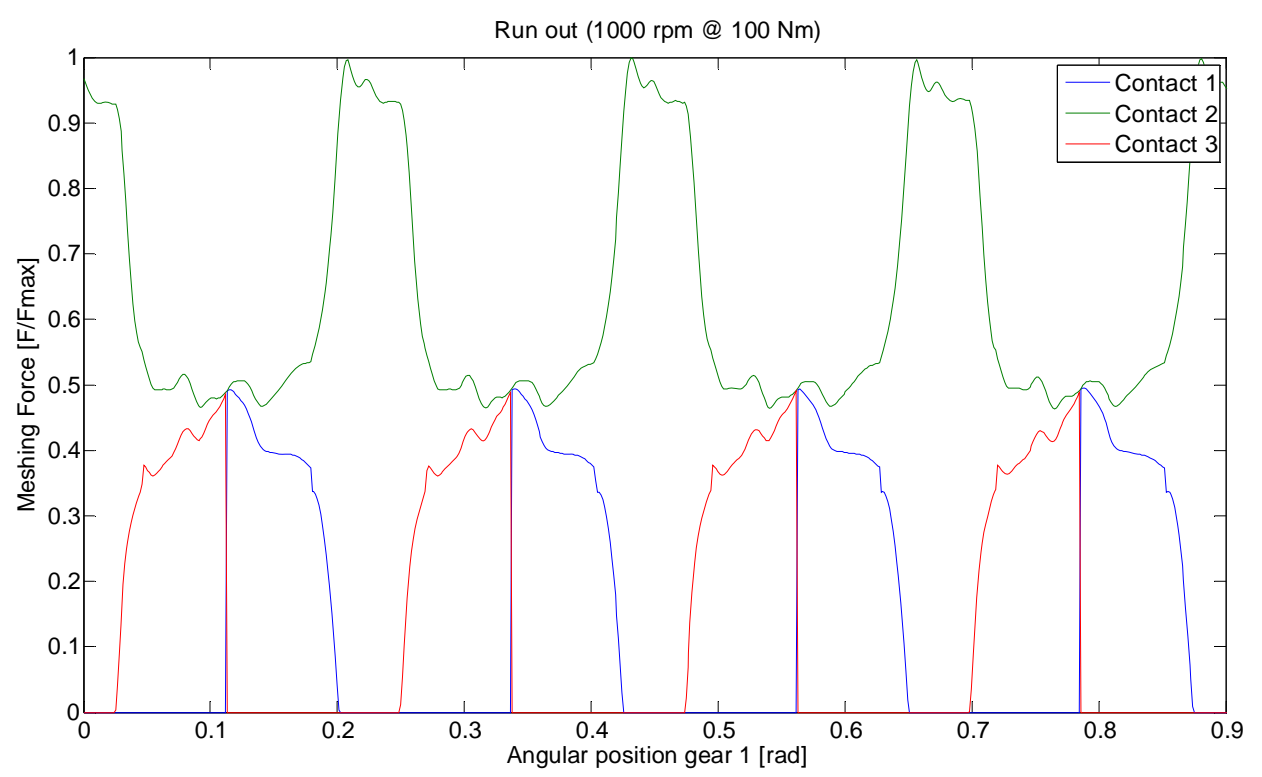

Fig. 17. 

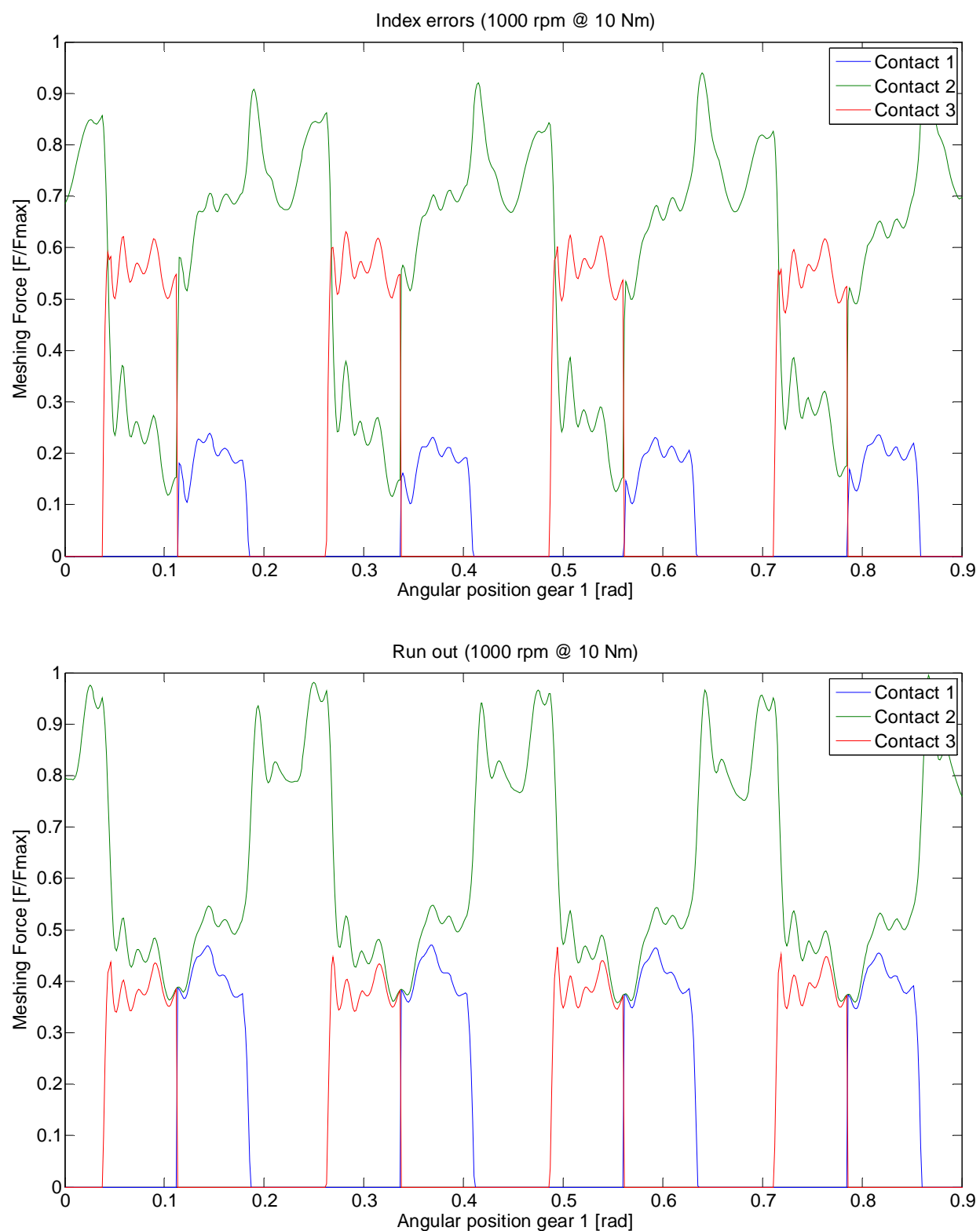

Fig. 16.- Normalized meshing forces 1000 rpm @ 10 Nm: a) (upper) Index errors; b) (lower) run out; 

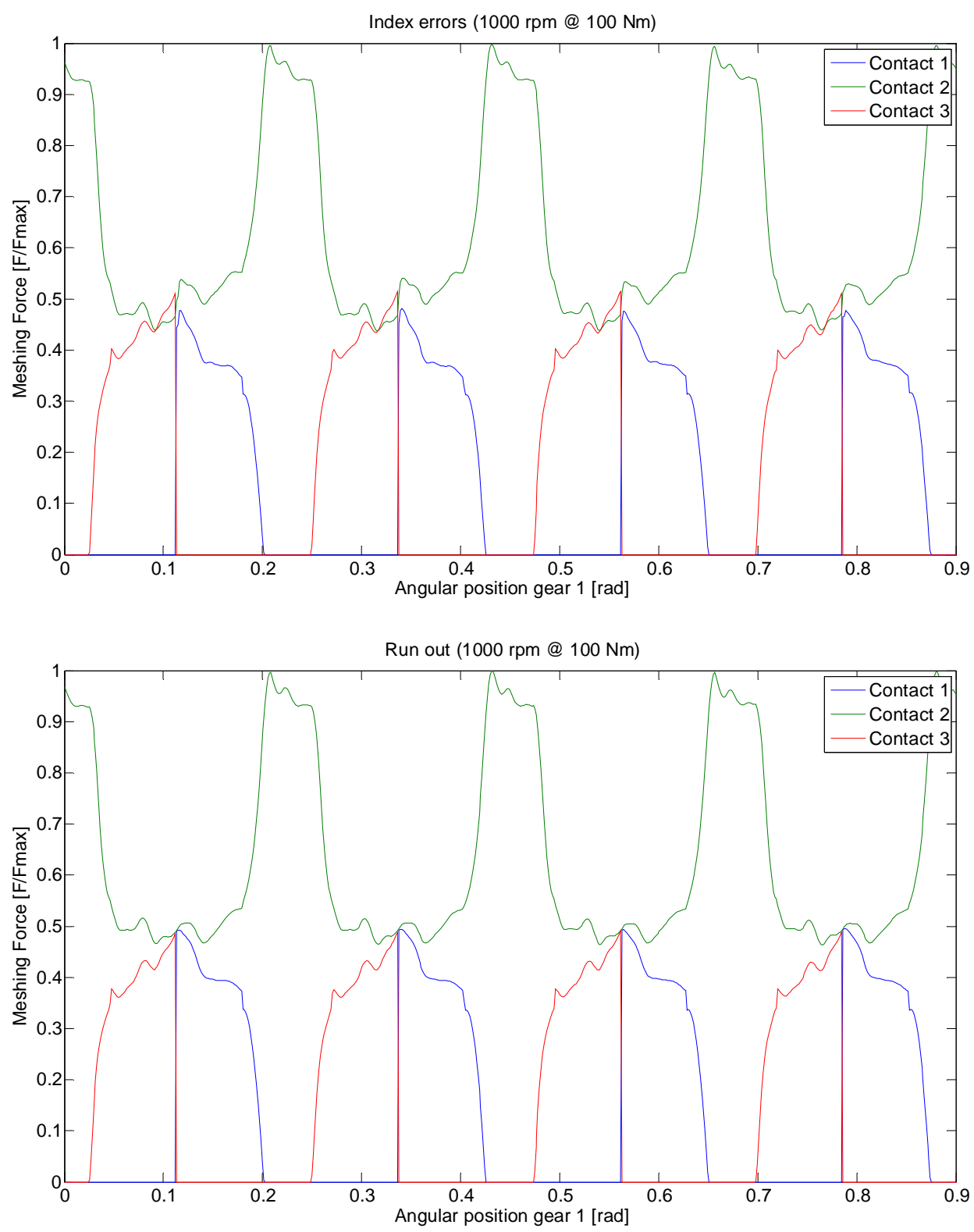

Fig. 17.- Normalized meshing forces 1000 rpm @ 100 Nm: a) (upper) Index errors; b) (lower) run out;

In order to complete the comparison between each kind of error, the effective pressure angle 


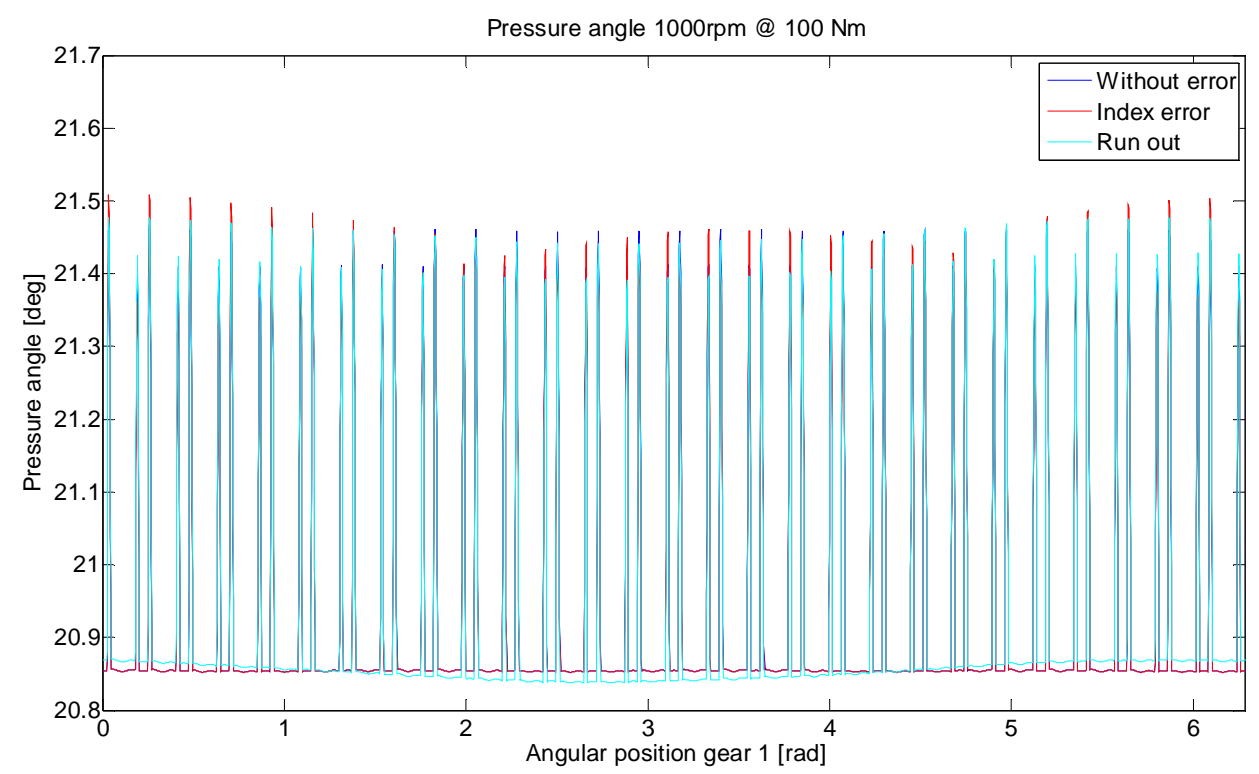

Fig. 18. In this figure, the same behavior described in quasi-static analysis can be observed. The subtle change in the nominal pressure angle, which was shifted around 20.85 degrees, was due to the bearing clearances and resulted in a largest gear center distance and therefore higher pressure angle. 

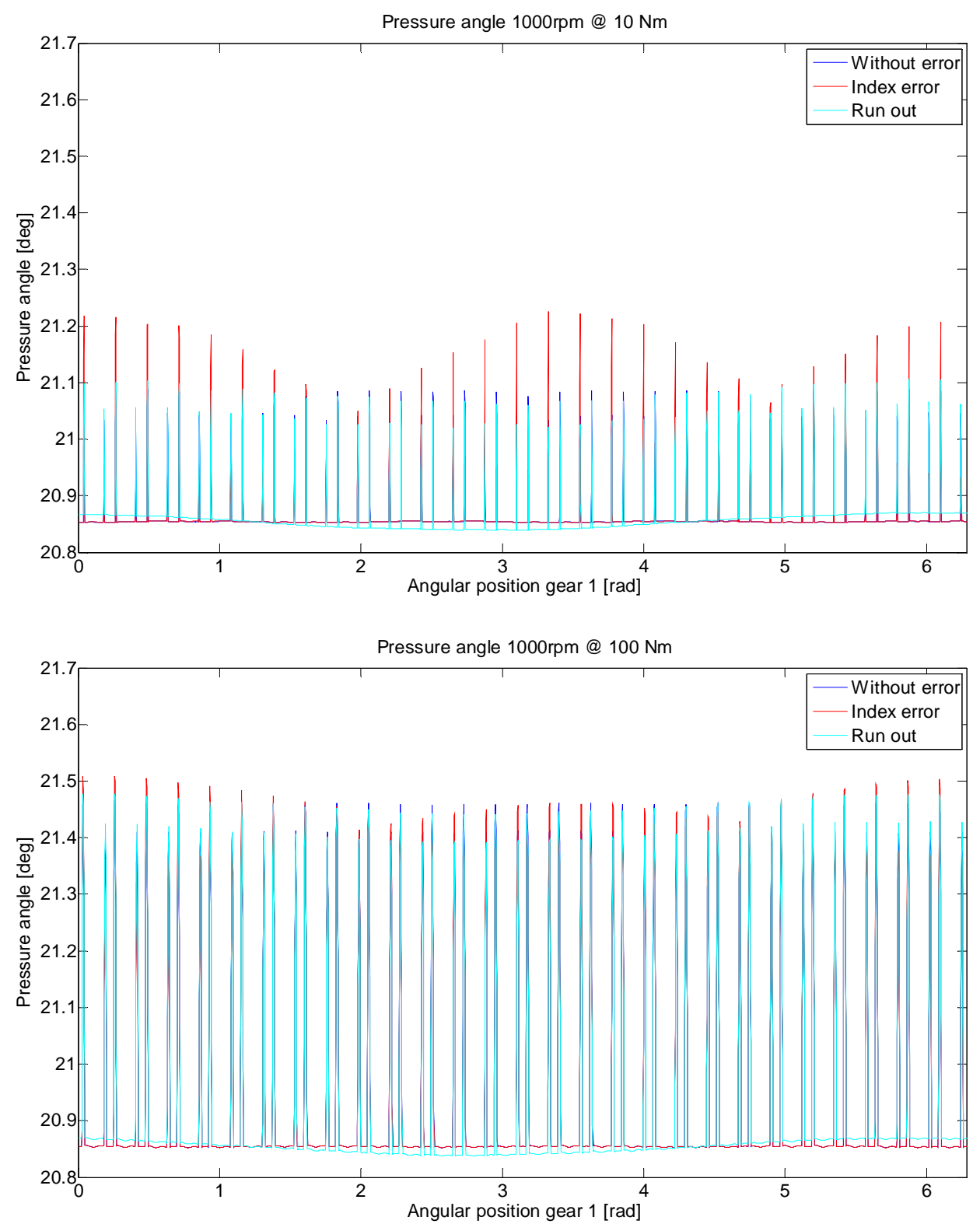

Fig. 18.- Comparison of effective pressure angle for normal conditions, index and run out errors @ $1000 \mathrm{rpm}$ a) (Upper) $10 \mathrm{Nm}$; b) (Lower) $100 \mathrm{Nm}$.

Hence, it can be concluded from the previous paragraphs that the analysis of LTE, LSR and pressure angle could be used to identify the presence of index or run out errors. Nevertheless, in practical applications, it is not possible to derive these magnitudes from conventional measurements. Instead, the most common technique used for this purpose is the analysis of vibrations recorded by seismic accelerometers in the transmission case (near the gear shaft bearing). These vibrations will be the result of the excitation forces at bearings and the dynamic response of the case. For the sake of simplicity, in this work, the case dynamic was neglected and the attention was focused on the bearing forces which in fact contained the information regarding index and run out errors.

With this aim, the forces obtained in the LOA at bearings, designated as 1b1 (see Fig. $1)$, 


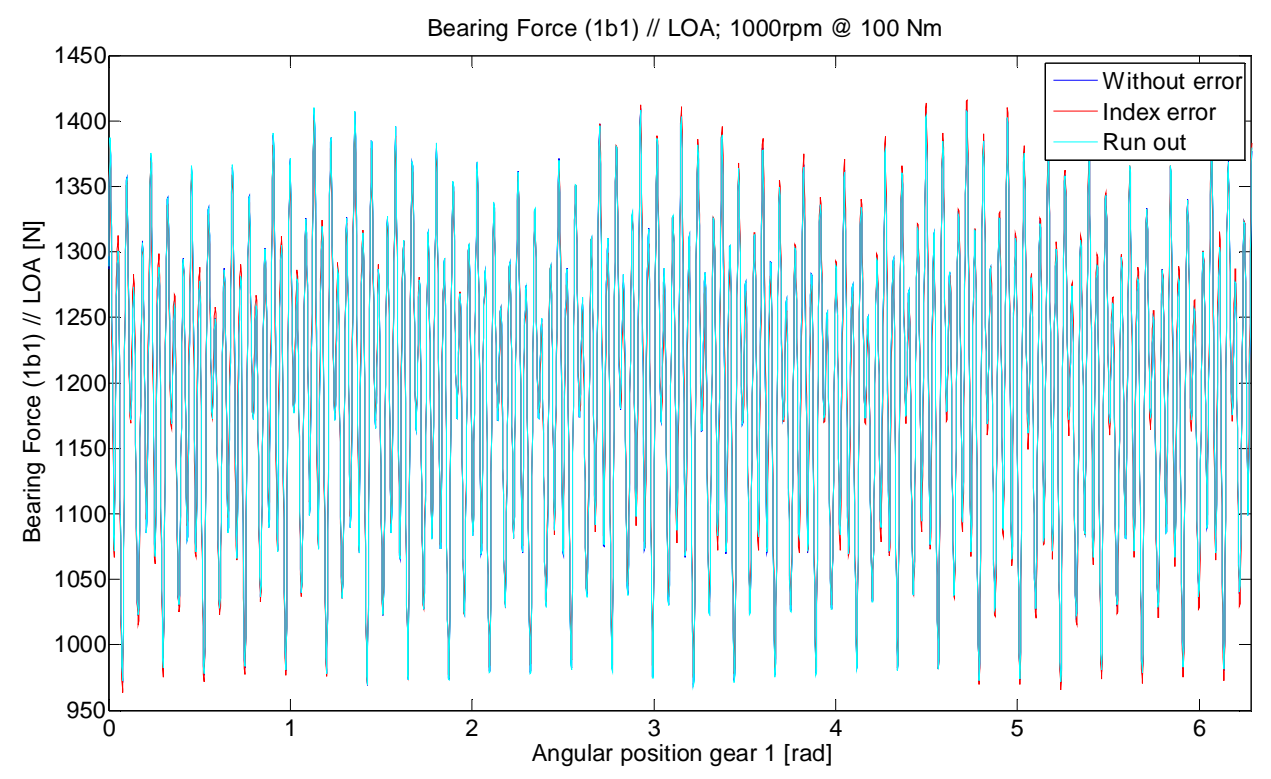

Fig. 19, corresponding to a complete revolution of gear 1 for the extreme values of torque considered in simulations $(10 \mathrm{Nm}$ and $100 \mathrm{Nm})$. When the applied torque was 10 $\mathrm{Nm}$, the differences between the resultant forces obtained with (in red) and without (in blue and cyan) index errors can be distinguished easily, while the consequences of index errors are less evident when torque was $100 \mathrm{Nm}$. Furthermore, comparing run out and without error signals of bearing force, it can be appreciated that is not easy to identify discrepancies between signals in both torque values (happened the same for all the torque values). Moreover, the reader could appreciate the consequences of bearing variable compliance which is the responsible of the force fluctuation around 3.5 times per turn that is much more evident for lower torque. 

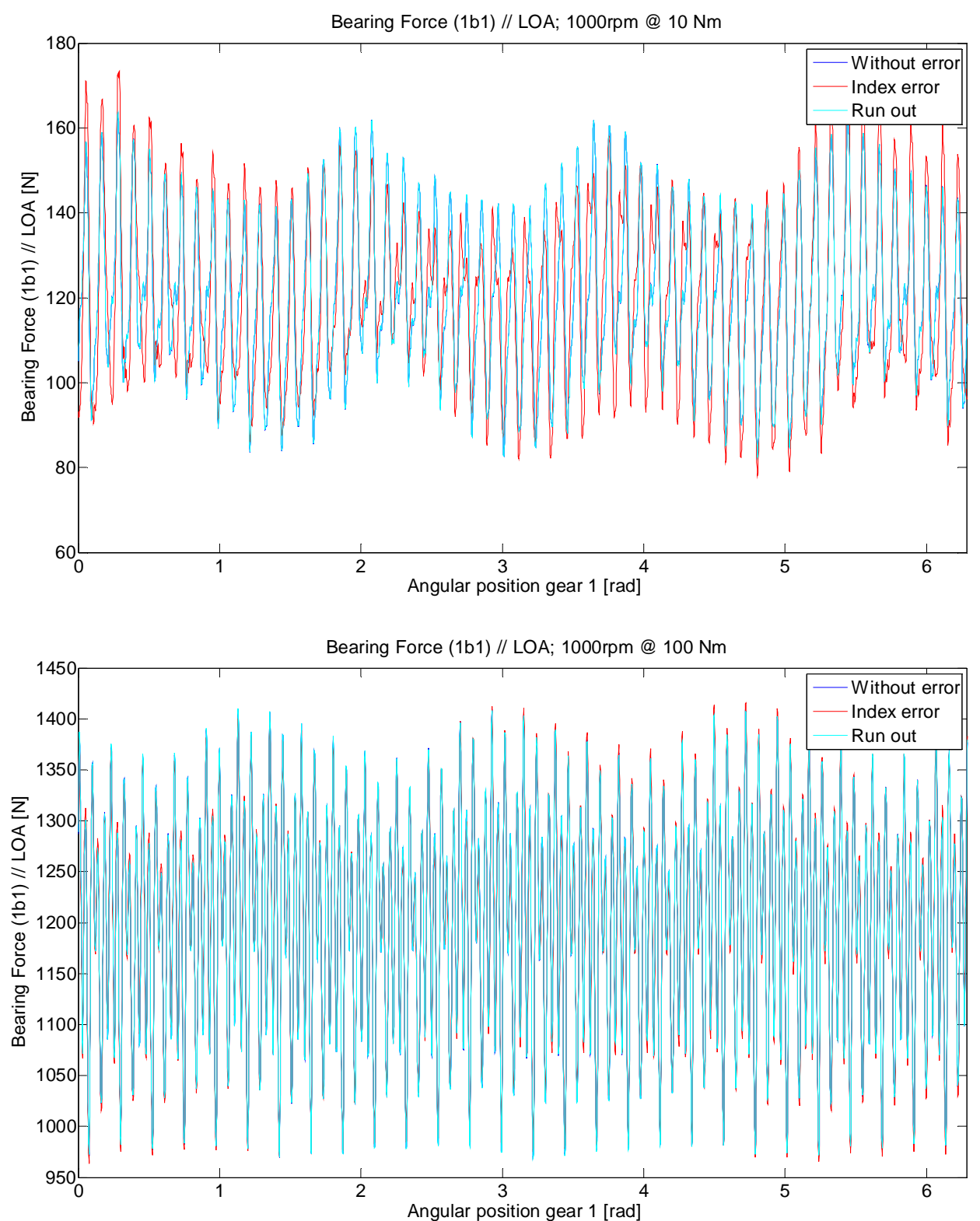

Fig. 19.- Bearing force in the so-called bearing $1 b 1$ for normal, index and run out errors: a) 1000 rpm@10 Nm; b) 1000 rpm@100 Nm.

In Fig. 20, it is presented the frequency spectrum corresponding to the bearing force time signals described above. It can be observed a similar pattern to that obtained in the case of LTE. Low torque provided a better scenario for identification of index errors while run out were not clearly distinguish, although it was possible to discern how it results in slightly wider GMF harmonics as a consequence of modulation by the shaft frequency. This modulation cannot be appreciated better since the spectra resolution was reduced because only five turns of the driven gear were simulated. 

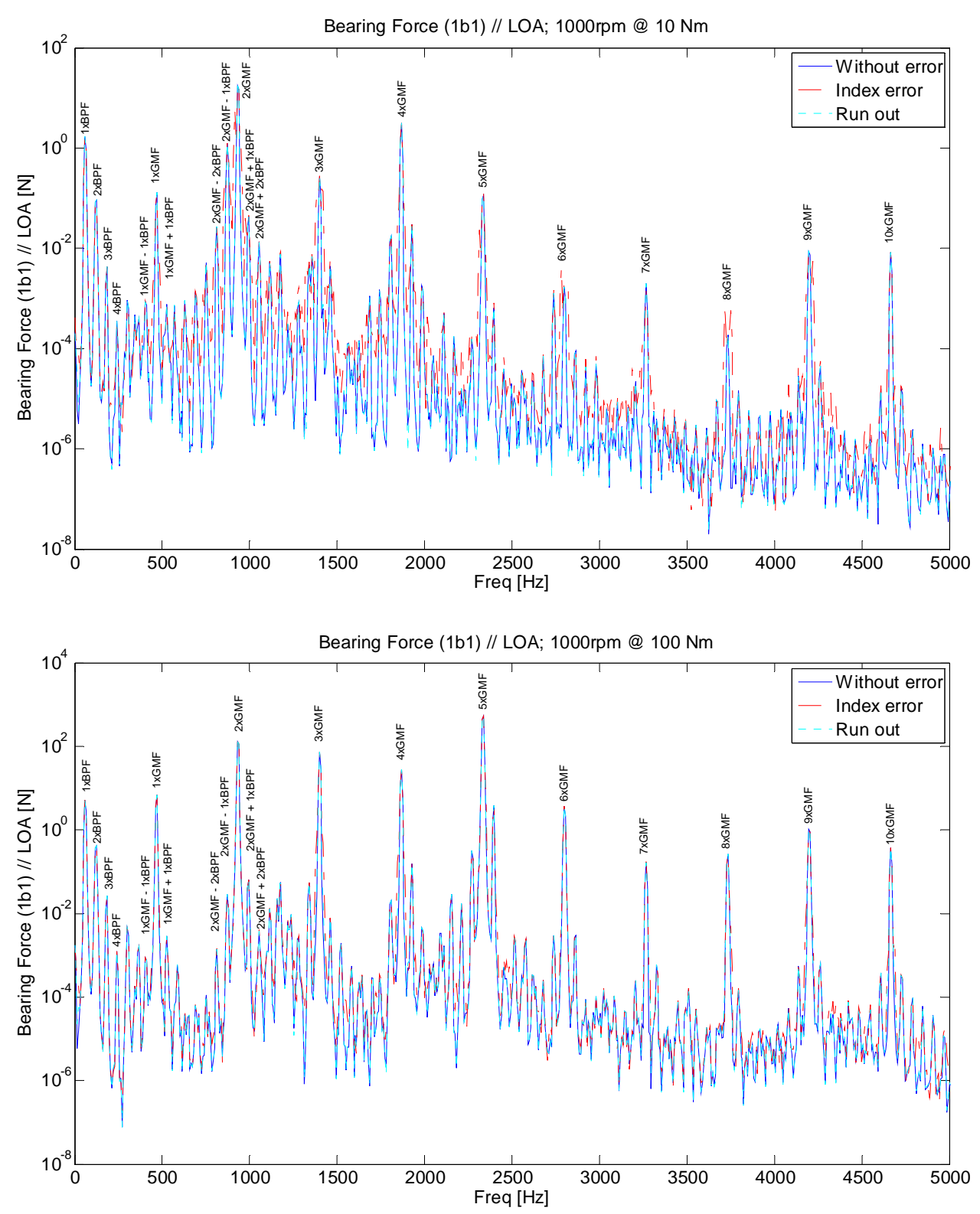

Fig. 20.- Spectrum of the transmitted force in the LOA on the so-called bearing $1 \mathrm{~b} 1$ without errors, index error and Run out; a) (Upper) 1000 rpm @ 10Nm; b) (Lower) 1000 rpm @ 100 Nm

Much more interesting were the results obtained when bearing forces were deeper processed by Amplitude and Phase demodulation (AM and PM). Fig. 21; Fig. 22 and Fig. 23 show the force record filtered around the 2 th GMF harmonic corresponding to a transmitted torque of $20 \mathrm{Nm}$ for each case considered. In absence of defects, it can be appreciated some peaks at the ball pass frequency and its harmonics (in this case around $61.04 \mathrm{~Hz}$ due to the spectral resolution). In contrast, when index or run out errors were considered, additional peaks appeared at the shaft rotation frequency $16.6 \mathrm{~Hz}$ (corresponding to the bin at 18.31 due to the spectra resolution). The amplitude of the peaks at the rotation frequency was higher for index errors than for run out, although the LTE was similar in all the cases. When other torques or GMF were chosen, a similar pattern appeared in the spectra always with lower amplitudes at the shaft rotation in the case of run out with respect the index errors. 

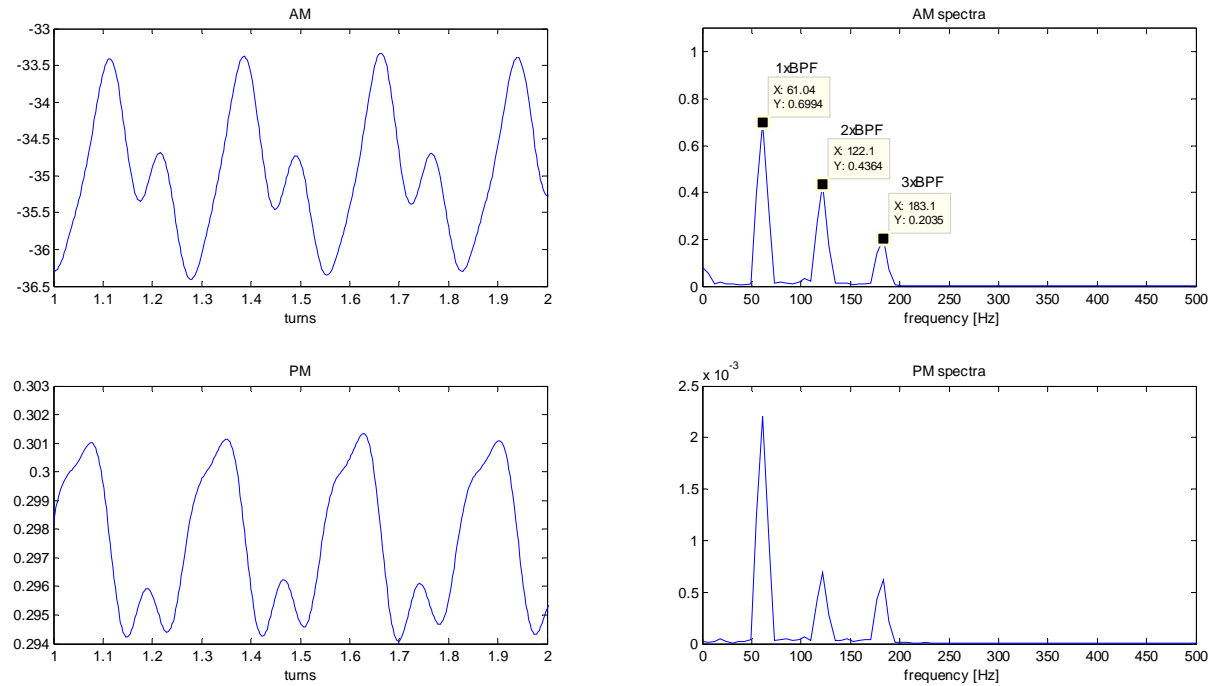

Fig. 21.- AM (Upper) and PM (Lower) demodulation of LOA force at so-called bearing $1 \mathrm{b1} 1000$ rpm@ 20 Nm without errors. Left Column Angle, Right Column Frequency spectra.
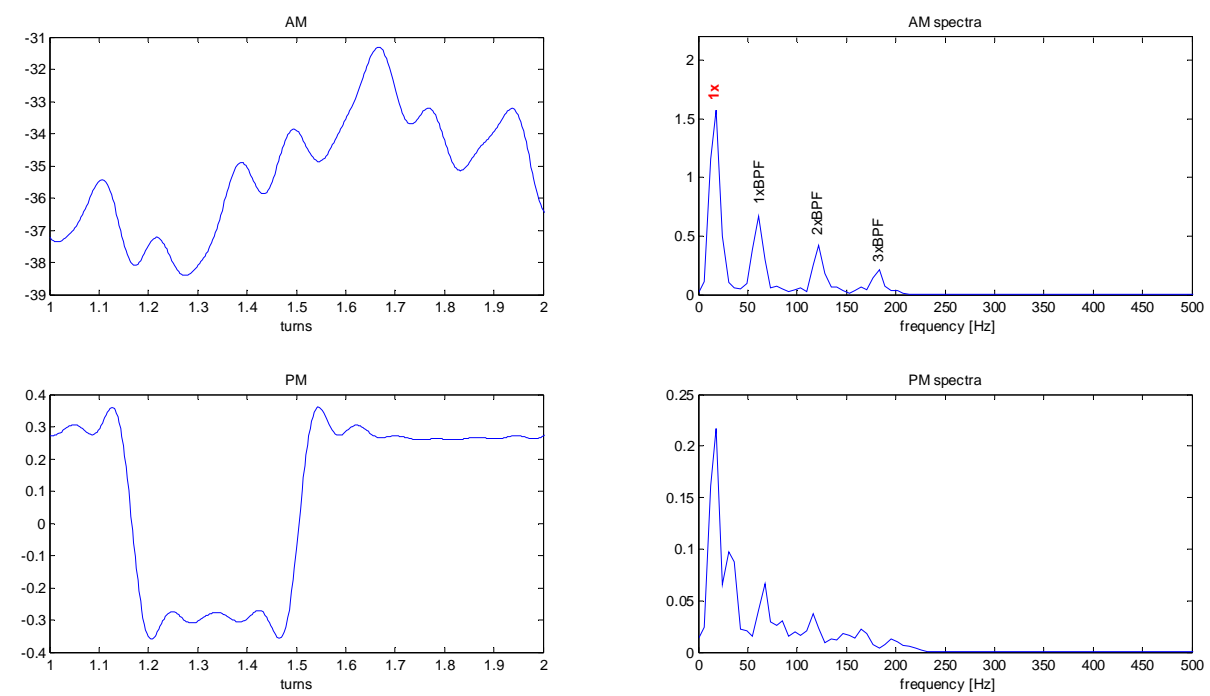

Fig. 22.- AM (Upper) and PM (Lower) demodulation of LOA force at so-called bearing $1 \mathrm{~b} 11000$ rpm@ 20 Nm with Index errors. Left Column Angle, Right Column Frequency spectra. 

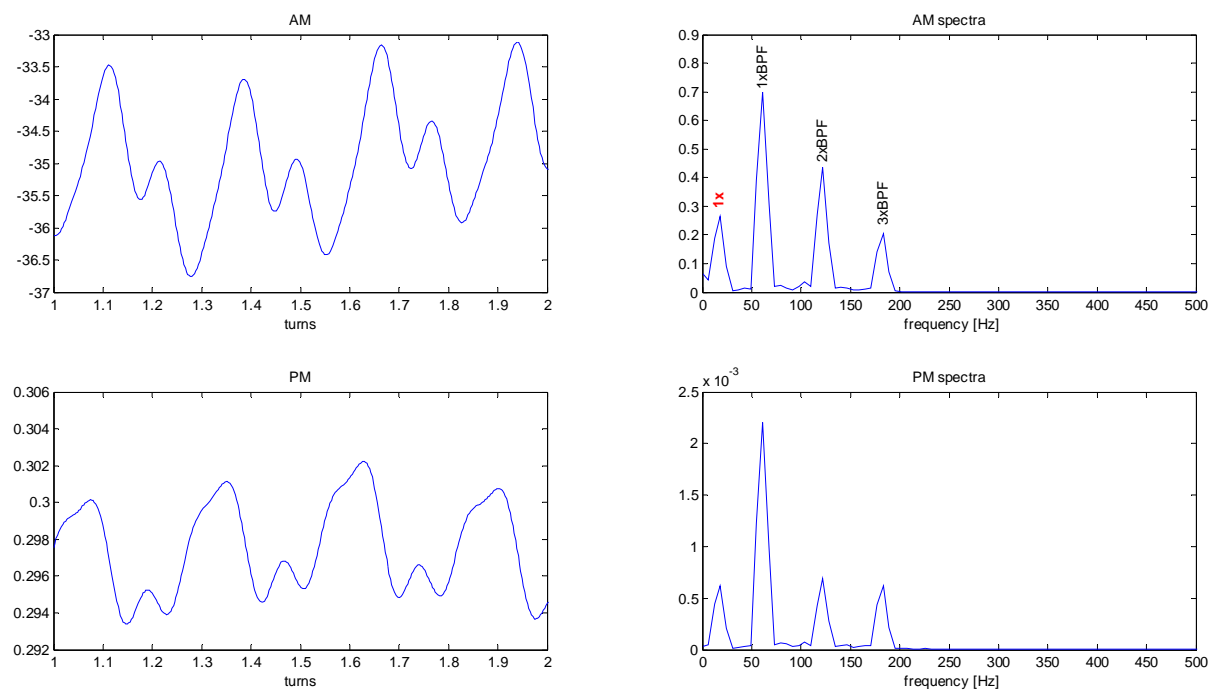

Fig. 23.- AM (Upper) and PM (Lower) demodulation of LOA force at so-called bearing $1 \mathrm{b1} 1000$ rpm @ 20 Nm with Run out. Left Column Angle, Right Column Frequency spectra.

\section{Conclusions}

An enhanced model for the study of dynamic behavior of gear transmissions in presence of index and run out errors has been presented in this paper. An example of application has been assessed in static and dynamic regimes, showing the differences among the gears parameters, such as LSR, LTE and forces, with run out, index error and in absence of errors. These results have been illustrated not only in the time domain but in the frequency domain using some demodulation techniques which made easier the comprehension of the outcomes. From the results, some differences were appreciated particularly on the LSR which should be considered in the design stage as they will result in an increment of the tooth root stress. This means that index errors become critical not only from the point of view of final noise and vibration behavior but because they may lead to high overloads which could decrease the transmission life expectancy. Moreover, demodulation techniques have shown higher amplitudes at the shaft rotation when index errors were considered while run out lead to lower values. This fact could be used to discern the origin of the modulation by assessment of experimental measurements.

Acknowledgements. The authors would like to acknowledge Project DPI2013-44860 funded by the Spanish Ministry of Science and Technology and COST ACTION TU 1105 for supporting this research.

\section{References}

1. Viadero F., Fernandez del Rincon A., Sancibrian R., Garcia P., de-Juan, A.: A model of spur gears supported by ball bearings. WIT Trans. Modelling and Simulation, 46, 711-722 (2007)

2. Fernandez del Rincon A., Viadero F., Iglesias M., García P., De-Juan A., Sancibrian R.: A model for the study of meshing stiffness in spur gear transmissions. Mechanism and Machine Theory, 61, 30-58 (2013)

3. Fernandez del Rincon A., Viadero F., Iglesias M., Garcia Fernandez P., de-Juan A., Sancibrian R.: Load effects on the dynamics of spur gear transmissions. ESDA2010-25090, 369-378 (2010)

4. Fernandez del Rincon A., Viadero F., Iglesias M., de-Juan A., García P., Sancibrian R.: Effect of cracks and pitting defects on gear meshing. Proc IMechE Part C: J Mech Engineering Science 226, (11), 2805-15 (2012) 
5. Fernandez del Rincon A., Iglesias M., de-Juan A., García P., Sancibrián R., Viadero F.: Gear transmission dynamic: Effects of tooth profile deviations and support flexibility. Applied Acoustics, 3,77(0),138-49 (2014)

6. Remmers E.P.: Gear mesh excitation spectra for arbitrary tooth spacing errors, load and design contact ratio. Journal of Mechanical Design 100, 715-722, 1978.

7. Padmasolala G., Hsiang, H. Lin: Influence of tooth spacing error on gears with and without profile modifications, $8^{\text {th }}$ International Power Transmission Conference, ASME, Baltimore, Maryland, September 10-13, 2000.

8. Spitas C., Spitas V.: Calculation of overloads induced by indexing errors in spur gearboxes using multi-degreeof-freedom dynamical simulation. Proceedings of the Institution of Mechanical Engineers, Part K: Journal of Multi-body Dynamics 220, 273- 282, 2006.

9. Handschuh M. J., Kahraman A., Milliren M.R.: Impact of tooth spacing errors on the root stresses of spur gear pairs, Journal of Mechanical Design 136, 061070(1)-(10), 2014.

10. Shengxiang J.: Dynamics Modelling and Diagnosis of Spur Gearbox Faults, PhD Thesis, Curtin University of Technology, 2004.

11. Velex P., Maatar M.: A mathematical model for analyzing the influence of shape deviations and mount-w12ing errors on gear dynamic behavior, Journal of Sound and Vibration 191, 629-660, 1996.

12. Jia S., Howard I., Wand J.: The dynamic modelling of multiple pairs of spur gears in mesh, including friction and geometrical errors, International Journal of Rotating Machinery, 9(6), 437-442, 2003.

13. Harris T., Kotzalas M.: Rolling Bearing Analysis, John Whiley \& Sons, Inc. 2001. 